\title{
Productividad, capacidad tecnológica y de innovación, y difusión tecnológica en la agricultura comercial moderna en el Perú: un análisis exploratorio regional
}

Mario Tello

\begin{abstract}
RESUMEN
El presente trabajo, de naturaleza exploratoria, analiza y estima las interrelaciones entre la capacidad tecnológica y de innovación (CTI), la difusión de buenas prácticas tecnológicas y la productividad laboral de unidades productivas del sector agrícola comprendido por jefes de familia de condición jurídica de persona natural los cuales venden su producción al mercado (interno y/o externo). La fuente primaria y básica de información de estos productores de la agricultura comercial moderna es el Censo Nacional Agropecuario de 2012. Los tres principales resultados de las estimaciones señalan: que el tamaño de la unidad productiva, el capital humano acumulado (en niveles de educación) del productor y la distancia geográfica entre la ubicación de la unidad de producción y la capital del distrito de dicha ubicación fueron los principales factores que incidieron en la capacidad tecnológica y de innovación. Esta capacidad conjuntamente con los efectos de derramamiento derivados de las asociaciones de los agricultores determinó el uso y difusión de las seis buenas prácticas tecnológicas. Finalmente, el stock de tierras por trabajador fue el principal determinante de la productividad laboral de cada una de las regiones del Perú.
\end{abstract}

Palabras clave: capacidad tecnológica y de innovación, buenas prácticas tecnológicas y productividad laboral.

Clasificación JEL: Q16, R11

\footnotetext{
* Profesor principal del Departamento de Economía de la Pontificia Universidad Católica del Perú. Este trabajo es una versión recortada del informe final del proyecto sobre productividad e innovación financiado por FAO y MINAGRI. El autor agradece el apoyo brindado de los asistentes Paulo Matos y Alfonso Rodríguez y los pertinentes comentarios de dos árbitros debido a los cuales, y a mi entender, permitieron mejorar la presentación de las ideas claves del estudio.
} 


\title{
Productivity, Technology and Innovation Capacity and Dissemination of Technology in Modern Commercial Agriculture in Peru: A Regional Exploratory Analysis
}

\begin{abstract}
This paper, exploratory in nature, analyzes and estimates the relationships between the technological and innovation capacity (CTI), diffusion of good technological practices and labor productivity of productive units of the agricultural sector undertaken by family chiefs selling their production to (domestic and external markets) and of legal conditions of 'natural persons' of Peru. The main source of information is the National Agricultural Census of 2012. The three main results of the estimations point out that unit sizes, family chiefs' human capital accumulation and the geographic distance between the location of the productive unit and the capital of the district of that location were key statistical factors that determined the producer technological and innovation capacity. This CTI together with the spillover effects coming from producers associations determined the diffusion and use of technological good practices. Finally, the stock of land per workers was the key determinant of labor productivity in all the regions of Peru.
\end{abstract}

Keywords: Technological and innovation capacities, good technological practice and labour productivity

JEL Codes: Q16, R11

\section{INTRODUCCIÓN}

Según datos oficiales del INEI (2014) el 99,4\% de las 2260973 unidades agropecuarias censadas del Censo Nacional Agropecuario, CENAGRO; 2012 pertenece a la condición jurídica de persona natural, y el $80 \%$ de estas unidades disponen de menos de cinco hectáreas para sus actividades agropecuarias. De otro lado, 479312 de estos productores individuales tienen como principal actividad la venta de productos agrícolas. Estos productores denominados 'unidades de la agricultura comercial moderna (UACM)' por las características de flexibilidad, capacidad de innovar (en los ámbitos productivo, comercial y empresarial), uso de buenas prácticas ambientales y laborales, respuesta oportuna a las exigencias del mercado, e inversión en tecnología con la finalidad mejorar la eficiencia de sus operaciones productivas, comerciales y logísticas, y ventas de la producción a los mercados interno y externo (señaladas por Gómez, 2008), pueden potencialmente lograr ser unidades de producción competitivas. La producción de las UACM comprende productos tradicionales y no tradicionales de exportación.

A pesar de dicho potencial, otras de las características singulares de parte de estas unidades productivas (en su mayoría pertenecientes al sector agrícola informal ${ }^{1}$ ) es la baja

\footnotetext{
1 De acuerdo a la definición de ICLS-ILO (1993) informales agrícolas son productores independientes sin registro legal y/o que no cuenten con libros contables.
} 
productividad laboral ${ }^{2}$ de sus emprendimientos. Estimados del autor indican que dicha productividad del universo informal agropecuario representó en 2012 el 13\% del PBI per cápita del Perú (medido a precios de 2007). Adicionalmente, Tello (2014a) ha presentado evidencia que indica que incrementos de la productividad laboral en el sector agropecuario peruano de emprendimientos de personas naturales inciden positivamente en el nivel de ingresos reales de las familias y el índice de desarrollo humano, y negativamente sobre la incidencia de la pobreza y la extrema pobreza.

Bajo este contexto, el presente estudio presenta 'evidencias no-experimentales' y de naturaleza exploratoria de los factores que determinan la productividad laboral (PL) de las unidades productivas de la agricultura comercial moderna. De estos factores, se enfatiza la incidencia de dos factores tecnológicos: la capacidad tecnológica y de innovación (CTI) y la difusión de las buenas prácticas tecnológicas (DBP) ${ }^{3}$. En consecuencia, el objetivo del trabajo es analizar y estimar las interrelaciones entre la CTI, la difusión de buenas prácticas tecnológicas y la productividad laboral de los agricultores comerciales modernos del Perú y sus regiones en 2012.

El trabajo comprende cinco secciones. Sección I sintetiza la literatura de las interrelaciones planteadas. Sección II describe las especificaciones ad hoc que interrelaciona la capacidad tecnológica de innovación, la difusión tecnológica y la productividad laboral y plantea la estrategia de estimación de estas especificaciones. Sección III presenta los datos y un análisis descriptivo de los mismos. Sección IV presenta las estimaciones. La última y quinta sección resume las principales conclusiones del estudio.

\section{SINTESIS DE LA LITERATURA ${ }^{4}$}

Esta sección se centra de manera sucinta en los argumentos teóricos y evidencias empíricas de las interrelaciones entre la capacidad tecnológica y de innovación (CTI), la difusión de buenas prácticas tecnológicas y la productividad laboral de unidades productivas del sector agrícola. Con respecto a esta última, la literatura sobre los factores que determinan la productividad (factorial total o laboral) la resume Syverson (2011). A nivel de empresas, los factores internos y de control de estas son: i) el stock de capital físico y humano; ii) el tamańo de la empresa; ii) el talento de los administradores o gerentes de las firmas; iii) las buenas prácticas empresariales y tecnológicas; iv) la innovación tecnológica; v) el uso de tecnologías de información, vi) innovación y diversificación de productos.

\footnotetext{
2 Medido por el valor agregado por trabajador.

3 Datos recientes sobres estos aspectos indican: i) baja inversión del gobierno y empresas en investigación y desarrollo (I\&D), ii) bajos niveles de la capacidad de innovación; y iii) bajo crecimiento de la productividad total factorial para la economía peruana (WEF, 2014; Conference Board, 2014).

4 Referencias básicas de los temas y conceptos abordados en esta sección están listado en tres handbooks: desarrollo económico, HDE (1988-2010), economía de la innovación (Hall y Rosenberg, 2010), y economía de la agricultura (Gardner y Rausser, 2002; y Evenson y Pingali, 2009).
} 
De otro lado, factores 'externos' (en general) fuera del control de las empresas que también inciden en la productividad son: i) 'productivity spillovers' o 'los efectos de derramamientos'. Ejemplos de estos efectos son las 'aglomeraciones de empresas' o el grado de coordinación o asociación entre firmas y/o otros entes; ii) la competencia del mercado interno; iii) la competencia del mercado externo; y iv) las regulaciones y trabas burocráticas impuestas a las empresas.

En adición a esta lista de factores 'convencionales' que inciden en la productividad de las firmas, la literatura y evidencia empírica señala otros factores asociados al tipo de: a. economías y/o áreas geográficas sujeto de estudio, b. sectores productivos; c. organización empresarial; y d. género de los agentes que realizan los emprendimientos productivos. Así, Webb (2013) señala que para los datos de INEI-ENAHO (2014) del año 2008 existe un efecto estadísticamente positivo de la aglomeración espacial y de la dispersión geográfica sobre los ingresos de las actividades agropecuarias en las áreas rurales del Perú. Un canal mediante el cual dichos factores afecten a la los ingresos es por sus efectos sobre la productividad laboral. De otro lado, en las estimaciones de los determinantes ${ }^{5}$ de la productividad laboral en el sector agrícola de 51 áreas geográficas (prefecturas) de 2003, Pollyzos y Arabatsis (2006) encuentran que el capital humano, la infraestructura de irrigación, la distancia geográfica entre el centro de producción y la capital del distrito donde se localiza el centro, y el tamaño de las áreas cultivadas agrícolas fueron los factores estadísticamente más relevantes en la determinación de la productividad laboral agrícola de las 'regiones' de Grecia.

Otro grupo de estudios se han concentrado en la relación negativa entre productividad (laboral y de la tierra) y el tamańo de la unidad productiva (por ejemplo, Ayalew y Deininger, 2014; Assunção y Braido 2007; Barrett, Bellemare y Hou. 2010). La incidencia negativa del acceso y restricciones al crédito sobre la productividad de la tierra en el Perú fue estimada por Guirkinger y Boucher (2008). Estos factores potencialmente pueden incidir sobre la productividad laboral. Basado en una muestra de 162 países desarrollados y en desarrollo, Lagakos y Waugh (2013) por su parte arguyen que la baja productividad laboral del sector agropecuario con respecto a los sectores no agropecuarios se debe a la menor calificación de la mano de obra que labora en dicho sector. Finalmente los estudios de la $\operatorname{OECD}(2012,2011)$ y Alston $(2010)$ resumen una extensa literatura de los determinantes de la productividad en el sector agropecuario en los países desarrollados. De estos los mayormente enfatizados son: el tamaño de la unidad agropecuaria, la intensidad de los factores, la especialización de la unidad, el capital humano, el medio ambiente, la inversión e infraestructura, las regulaciones y políticas económicas, y la inversión en investigación y desarrollo (I\&D) que conduzca a la innovación y difusión

\footnotetext{
5 Los factores que incluyen son: i) tamaño de las parcelas (el número de hectáreas cultivadas); ii) infraestructura productiva (tractores usados); iii) el tamaño en número de trabajadores de las actividades agrícolas, iv) infraestructura de irrigación; v) divisibilidad de las parcelas, vi) medio ambiente y distancia geográfica; vii) educación; viii) demanda (población del área geográfica); e ix) inversión.
} 
tecnológica en el campo. De acuerdo a la disponibilidad de la información y tomando como base el conjunto de factores descritos, la sección siguiente selecciona las variables claves que inciden en la productividad laboral en la agricultura moderna peruana.

El segundo concepto relacionado con la productividad es el de la capacidad de inno$\operatorname{var}^{6}$. Este concepto -resultado de los procesos I\&D, también ha sido foco de análisis de una relativamente extensa literatura. En términos generales, la innovación es conceptualizada como "la implementación de un producto, proceso productivo [innovación tecnológica], método de comercialización o de organización [innovación no-tecnológica] nuevo o significativamente mejorado en actividades productivas" (Hall, 2011). De otro lado, la capacidad tecnológica no solo comprende la capacidad de la firma de poder innovar sino de también la capacidad de absorción tecnológica (Bell y Pavitt, 1993). De acuerdo con Zahra y George (2002), la capacidad de absorción tecnológica es la habilidad de una firma para reconocer el valor de nueva información externa, adquiriéndola, asimilándola (capacidad potencial), transformándola y explotándola para fines comerciales (capacidad realizada). Crepon, Duguet y Mairesse (1998), con respecto a los factores que indicen las decisiones de inversión y capacidad de innovar, señalan que para una firma 'produzca' o tenga la 'capacidad tecnológica' de innovación' requiere: incentivos para 'invertir' en innovación, formas de apropiarse los 'beneficios económicos' derivados de la innovación, acceso a información y conocimientos de 'otros entes', y ciertas características internas y externas a la firma que viabilicen dicha innovación (por ejemplo, tamaño y acceso al financiamiento). Estos factores que inciden en la capacidad de innovar serán tomados en cuenta en la siguiente sección. Aunque las unidades familiares agrícolas pueden tener 'racionalidades' distintas a las firmas capitalistas ${ }^{7}$, los factores considerados (como acceso a la información y financiamiento, tamaño de las unidades de producción, y los incentivos a innovar) pueden ser relevantes también para dichas unidades. Adicionalmente las unidades de agricultura moderna pueden también tener racionalidades capitalistas de acuerdo a las características señaladas por Gómez (2008).

El tercer y último concepto que se interrelaciona con la productividad y la capacidad de innovar es el de difusión tecnológica. Según Geroski (2000) y Stoneman (2002) dicha difusión se circunscribe al uso de nuevos 'conocimientos y buenas prácticas tecnológicas' por parte de las unidades productivas. El proceso de difusión tecnológica comprende además otros aspectos tales como: i) el proceso de comunicación e información de una innovación (por ejemplo, Rogers, 1995 y Hall, 2004); ii) la tasa de introducción de la innovación en tiempo y en número de personas (por ejemplo, Griliches, 1957 y Rosenberg, 1972), y iii) la capacidad de absorción de la innovación (por ejemplo

\footnotetext{
6 Referencias básicas de los temas y conceptos abordados en esta sección son tres handbooks: desarrollo económico, HDE (1988-2010), economía de la innovación (Hall y Rosenberg, 2010), y economía de la agricultura (Gardner y Rausser, 2002; y Evenson y Pingali, 2009).

Por ejemplo los modelos de familias agropecuarias de Taylor y Adelman (2003).
} 
Cohen y Levinthal, 1990) o de imitar tecnología foránea (Barro y Sala-Martin, 1995). Dos factores claves que determinan la difusión tecnológica son la capacidad tecnológica y de innovación (Bell y Paviit, 1993) y la conectividad como una fuente de información y diseminación del conocimiento tecnológico productivo (Rogers, 1995).

Pardey, Alston y Ruttan (2010), por su parte, señalan diversos aspectos particulares de la innovación y difusión tecnológica en el sector agropecuario. Entre otros: la especificidad espacial de las tecnologías agrícolas y sus implicaciones sobre las externalidades geográficas y la demanda de investigaciones adaptables, y los factores aleatorios concernientes al clima, las pestes y enfermedades generando una demanda de investigación de mantenimiento y seguros.

La literatura que interrelaciona la innovación, la difusión tecnológica y la productividad laboral en el sector agropecuario en países en desarrollo ${ }^{8}$ no es abundante comparado con aquella de otros sectores y de países desarrollados. De esta literatura se destacan los trabajos de Alene (2010), Dhehibi, Telleria y Aw-Hassan (2014), Warr y Suphannachart (2011) y Zant (2014) para los países fuera de la región latinoamericana. El primer trabajo señala la importancia de invertir en investigación y desarrollo (I\&D) en el desarrollo de la productividad total de factores del sector agropecuario en 52 países de África. El segundo trabajo señala la importancia del uso de sistemas de irrigación y la adopción de nuevas tecnología en la determinación de la productividad total de factores en Túnez. El tercer trabajo analiza el caso de la agricultura en Tailandia y encuentra que inversión pública en investigación tiene efectos positivos estadísticamente significativos sobre la productividad total de factores ${ }^{9}$. El cuarto trabajo analiza Malawi y se concluye que técnicas de cultivos orgánicos contribuyen a la productividad del maíz no subsidiado en dicho países.

Los trabajos en la región latinoamericana y el Caribe se han concentrado en: descripciones de los sistemas de innovación de la agricultura (World Bank, 2012), estimaciones de la productividad en el sector (Ludeña, 2010), y en casos de estudios de pequeńas empresas del sector (BID, CEPAL, OEA, 2011). De igual manera, los estudios sobre la productividad e innovación en el sector agropecuario Peruano se han limitado a trabajos de casos o muestras muy pequeñas con débiles fundamentos teóricos. Entre los principales trabajos se destacan el compendio de nueve estudios de FINCyT-CIES (2010) de los cuales cuatro corresponden al sector agropecuario ${ }^{10}$. Tres de estos trabajos se basan en el marco conceptual de la capacidad de absorción potencial y realizada (Zahra y

\footnotetext{
8 Los trabajos de Pardey, Alston y Ruttan (2010), $\operatorname{OECD~}(2011,2012)$ y Alston (2010) resumen la literatura de los efectos de la innovación y difusión tecnológica en el sector agrícola de los países desarrollados.

9 Si la actividad productiva se representa por Y=PTF.F(V), donde $Y$ es un índice de output de dicha actividad, PFT es la productividad total factorial y $\mathrm{V}$ es el vector de factores e insumos intermedios que se emplean en la producción de $\mathrm{Y}$, entonces $\mathrm{Y} / \mathrm{L}=\mathrm{y}=\mathrm{PL}=\mathrm{PTF} . \mathrm{F}(\mathrm{v})$. La productividad laboral $(\mathrm{PL}=\mathrm{y})$ depende de PTF y los empleos de factores e insumos por trabajador (v). Consecuentemente, aparte de v, la PL es determinada por los factores que determinan la PTF.

${ }^{10}$ Un quinto estudio del sector agroindustrial de naturaleza descriptiva es el de Huarachi, Larrea, Vargas, Heredia y Yamakawa (2010) quienes caracterizan el comportamiento tecnológico de empresas
} 
George, 2002; y Cohen y Levinthal, 1990) y en la metodología de casos para identificar diversos factores que nutren dicha capacidad.

El primer trabajo de Alvarez, D’Ipollito y Lemos de Aguilar (2009) analiza la empresa Pisco Payet concluyendo que la capacidad de absorción potencial y realizada de esta empresa es alta. De otro lado, los factores internos y externos que influenciaron a la innovación fueron: la organización interna de la empresa, la evolución tecnológica del cultivo y procesamiento de la vid, y el contexto industrial de apoyo del gobierno a las actividades del Pisco.

El segundo trabajo de Torres (2009) sobre la Central Piurana de Cafetaleros (CEPICAFE), la cual produce dos 'productos innovadores', azúcar integral ecológica (panela granulada) y mermelada (ecológica) de frutas tropicales, concluye que esta innovación en productos se debió a "la capacidad de la organización para absorber conocimientos externo construido en un proceso de aprendizaje entre expertos tecnólogos y productores asociados interactuando intensivamente con su entorno organizacional, institucional y político" (p. 868).

El tercer estudio de Del Castillo y Oviedo (2009) sobre la Central Piurana de Asociaciones de Pequeños Productores de Banano Orgánico - CEPIBO señala que el éxito de la adopción del paquete tecnológico se debió a la innovación organizacional y comercial sustentada en la integración social dentro de la comunidad.

El cuarto trabajo de Martínez, Rodríguez y Almeida (2009) usa el enfoque de 'desarrollo de capacidades' de Sen (1999) ${ }^{11}$ presenta el caso de 4 unidades familiares pecuarias de supervivencia las cuales adoptan distintos paquetes tecnológicos. Según la metodología de los autores, estos paquetes (como la introducción de riego por aspersión, de pastos mejorados o de métodos de engorde de vacunos) tienen un impacto importante en el aumento de productividad de las actividades tradicionales. Una buena parte de los factores considerados en estos cuatro estudios son incorporados en la metodología 'causal, no experimental y del universo de unidades agrícolas' del presente trabajo la cual permite validar o rechazar con mayor 'poder' estadístico los objetivos (generales y específicos) del mismo. Cabe además señalar que Kuramoto (2010), quien resume los nueve estudios

\footnotetext{
agro-industriales en café y granos secos, frutas y conservas, verduras frescas, colorantes naturales e insumos y productos alimenticios naturales.

11 Este consiste en la eliminación de algunos tipos de falta de libertad que dejan a los individuos pocas opciones y escasas oportunidades para ejercer su agencia razonada. En ese sentido, el desarrollo de capacidades apunta a la expansión de las libertades fundamentales, por lo que el desarrollo debe ser visto como el proceso de expansión de las libertades reales que disfrutan los individuos, buscando incrementar las oportunidades de las personas para ejercer sus derechos y capacidades donde el éxito de la innovación tecnológica está condicionado por la medida en que forme parte de un proceso que permita potenciar el capital humano y el capital social de los individuos, a través de los cuales se expanden las capacidades. De otro lado, la innovación tecnológica es concebida como un sistema de aprendizaje influenciado por factores endógenos (relacionados a características propias del individuo que permite cambiar una estructura o comportamiento, y asociados principalmente a aspectos socioculturales de un determinado grupo) y exógenos (relacionados a elementos externos a la unidad agropecuaria que permiten la introducción de las innovaciones tecnológicas.
} 
de innovación y de comportamiento tecnológico de FINCyT-CIES (2010), concluye que 'las empresas y sectores peruanos analizados se comportan de manera similar a lo encontrado a nivel internacional" (p. 32). Dicho comportamiento es consistente con las teorías, modelos, y conceptos plasmados en la literatura internacional.

Otros estudios complementarios que enfatizan diversos factores que inciden en la innovación, difusión tecnológica, y productividad son los de: PIADAL (2013) (el cual enfatiza el rol de las política públicas), Webb (2013) y Escobal (2000) (quienes enfatizan la conectividad geográfica), Damonte, Fulcrand, y Gómez (2008) (el énfasis es el 'capital social'), Trivelli, Escobal, y Revesz (2006) (donde la escala o tamańo de las unidades productividades es el factor enfatizado), y Trivelli, Escobal, y Revesz (2009) (donde la diversificación productiva es la variable foco).

\section{CAPACIDAD TECNOLÓGICA DE INNOVACIÓN, DIFUSIÓN TECNOLÓGICA Y PRODUCTIVIDAD: ESPECIFICACIONES Y ESTRATEGIA DE ESTIMACIÓN}

La sección anterior ha sintetizado la literatura sobre la capacidad tecnológica de innovación, la difusión tecnológica y la productividad laboral y sus interrelaciones. Esta sección toma como base esta literatura y postula tres especificaciones y sus interrelaciones de estos tres conceptos. Luego se presenta la estrategia de estimación de las ecuaciones presentadas.

La ecuación [2.1] corresponde a la especificación de la capacidad tecnológica y de innovación $\left(C T I_{i r}^{*}\right)$ del agricultor 'i' de la región ' $\mathrm{r}$ '

$$
\begin{aligned}
& C T I_{i r}^{*}=\operatorname{Prob}\left(D_{\text {CTIir }}\right)=X_{1 i r} \cdot \beta_{1 r}+\varepsilon_{1 i r} ; D_{\text {CTIir }}=1 s i \sum_{j} D_{j i r}>0.5 ; \\
& \text { caso contrario } D_{\text {CTIir }}=0
\end{aligned}
$$

Donde en esta ecuación, $C T I_{i r}^{*}$ es una variable latente (no conocida) que depende de un conjunto de factores $X_{1 i r}$ que la determinan. De acuerdo con Crepon, Duguet y Mairesse (1998) dos de esos factores se refieren a incentivos a 'invertir' en innovación y formas de apropiarse los 'beneficios económicos' derivados de la innovación. El nivel de educación (Edu) o acumulación de capital humano ${ }^{13}$ es la variable disponible que puede capturar estos factores. Un tercer factor, según estos autores, corresponden al acceso a información y conocimientos de 'otros entes' los cuales pueden estar relacionados a la ubicación de la unidad productiva con respecto a la capital del distrito donde el productor reside $\left(\right.$ Conex $\left.^{14}\right)$. La cercanía al distrito otorgaría estas ventajas a productores.

\footnotetext{
12 El año es 2012.

13 Variable continua que adopta hasta diez niveles de educación.

${ }^{14}$ Variable medida por el número de horas que se demora para llegar a la capital del distrito desde la unidad de producción.
} 
Otros factores considerados por Crepon, Duguet y Mairesse (1998) son características internas y externas a la firma que viabilicen dicha innovación. Por ejemplo, tamaño de la unidad de producción (como el número de trabajadores ${ }^{15}$, L, y extensión de tierras cultivadas, T), y género del jefe de familia, $D_{G E N}{ }^{16}$. Debido a que no se dispone de información directa de CTI*, esta es reemplazada por la variable binaria $D_{\text {CTIir }}$ que toma el valor de uno si $\sum_{j} D_{j i r}>0.5$, y cero si dicha desigualdad no se cumple. Las variables binarias $D_{j i r}$ representan nueve factores que configuran a la capacidad tecnológica y de innovación ${ }^{17}$. Estos factores son:

i) $\quad D_{E D U i r}=1$, si el nivel de educación del jefe de familia de la unidad productiva (up) es mayor o igual a secundaria completa de lo contrario el valor es cero;

ii) $D_{\text {ASOir }}=1$, si el jefe de familia de la unidad productiva está asociado a otro ente de lo contrario tiene valor de cero ${ }^{18}$;

iii) $D_{Y i r}=1$, si el productor percibe suficientes ingresos ${ }^{19}$ de lo contrario tiene valor de cero;

iv) $D_{P R O i r}=1$, si el productor es propietario de más del $50 \%$ del total de las parcelas de lo contrario tiene valor de cero;

v) $D_{\text {ATir }}=1$, si el productor recibió capacitación y asistencia técnica de lo contrario tiene valor de cero;

vi) $\quad D_{\text {TICir }}=1$, si el productor usa internet o lee publicaciones escritas de lo contrario tiene valor de cero;

vii) $D_{C R E D i r}=1$, si el productor obtuvo crédito para compra de capital (maquinaria y herramientas) de lo contrario tiene valor de cero;

viii) $D_{I N F i r}=1$, si el productor usa energía eléctrica o tractores de lo contrario tiene valor de cero;

ix) $\quad D_{X i r}=1$, si la producción se exporta de lo contrario tiene valor de cero.

La variable $D_{\text {CTIir }}$ pretende asociar de una manera directa a la capacidad tecnológica y de innovación del agricultor. Los factores que componen esta capacidad son los descritos por Crepon, Duguet y Mairesse (1998). La primera variable que compone la $C T I^{*}$ de la unidad productiva es el capital humano del jefe de familia. El nivel mínimo educativo

15 Este número incluye a los trabajadores permanentes y temporales empleados en la unidad agrícola.

16 DGEN es una variable binaria que toma el valor de 1 si el jefe de familia es mujer y cero si es hombre.

17 Aunque puede existir diversas alternativas de 'obtener' la variable CTI (por ejemplo, usando análisis factorial o creando una variable que agrupe y pondere de la manera diferente cada factor considerado) los resultados a ser descritos debajo y la simplicidad de la definición de la variable DCTI compensan las posibles deficiencias de esta variable con respecto a alternativas más sofisticadas las cuales pueden producir los mismos resultados estadísticos que la variable seleccionada como proxy a la variable CTI.

${ }_{18}$ Este variable también podría ser interpretada como el 'capital social' relevante para la unidad productiva. Otros entes comprende: asociaciones, comunidades, empresas, etc.

19 Note que esta variable es una percepción del agricultor y por lo tanto no requiere una definición predeterminada de suficientes ingresos. 
para que dicha capacidad pueda ser efectiva es secundaria completa ${ }^{20}$. Las siguientes dos variables $D_{Y i r}$ y $D_{\text {PROir }}$ representan las formas que las unidades productivas pueden apropiarse los resultados de la innovación. Las variables $D_{\text {CREDKir }}$ y $D_{I N F i r}$ corresponden a la infraestructura mínima requerida que sustenta la posibilidad de innovar de las unidades productivas. Las variables $D_{A T i}$, $D_{\text {TICir }}$ corresponden a los apoyos y herramientas técnicas que sustentan la capacidad de innovar. La variable $D_{A S O i r}$ representa las posibles efectos derramamientos (spillovers effects) que pueden se generado por las asociaciones. La novena variable $D_{\text {Xir }}$ provee información del conocimiento de los mercados externos. Dada las limitaciones de la base de datos usada en materia de innovación, los nueve factores considerados y que configuran la capacidad tecnológica de innovación son los más apropiados por que incluyen capacidades humanas (como educación, asistencia técnica, uso de tecnologías de información y comunicación), formas de asegurarse los beneficios de la innovación (como ingresos mínimos y propiedad de la tierra), infraestructura mínima de producción (vía disponibilidad de tractores o energía eléctrica y acceso al crédito para compra de capital) y formas de emplear dicha capacidad (como exportar) ${ }^{21}$. El umbral mínimo para que la variable $D_{C T \text { Tir }}$ tome el valor de uno lo define el valor de $\sum_{j} D_{j i r}$ donde cada variable 'j' corresponde a una de las nueve variables binarias descritas arriba. Para fines de la estimación dicho umbral es 50\%. De acuerdo a la información de la base de datos usada descrita en la siguiente sección los factores educación $D_{E D U}$, asociación $D_{A S O}$, ingresos $D_{Y}$, propiedad de la tierra $D_{P R O}$, e infraestructura $D_{I N F}$, son los que dominan en la muestra de agricultores y por consiguiente definen el apropiado umbral de $50 \%{ }^{22}$. Por otro lado, cuanto mayor es este umbral mayor es la exigencia de la disposición de capacidad tecnológica del agricultor. Los datos mostrados en la siguiente sección indican que con dicho umbral solo el 4,6\% de los agricultores (jefes de familia) tienen dicha capacidad. Este tamaño bajo de muestra de los agricultores en $C T I$ se debe a las relativas bajas muestras del nivel de educación y los otros cuatro factores considerados $\left(D_{X}, D_{\text {TIC }}, D_{C R E D}, D_{\text {INFRA }}\right)$. Con esta construcción de la variable $C T I^{*}$ y el umbral definido, la estimación de la ecuación [2.1] se interpretaría como la estimación de la probabilidad de que el agricultor 'i' de la región ' $r$ ' disponga de más del $50 \%$ de capacidad tecnológica de innovación en su unidad productiva. Con dicho nivel

${ }^{20}$ Para la definición de la variable $D_{C T P}$, la variable $D_{E D U}$ representa el nivel mínimo de capital humano que pueda contribuir a la formación de la CTI. De la muestra de 104130 agricultores solo el 21,6\% de ellos cumplieron con el nivel mínimo $D_{E D U}$. La variable $E D U$ en la ecuación [2.1] representa la incidencia de la acumulación del capital humano sobre dicha capacidad.

21 Tello (2013) ha presentado evidencias que señalan que para exportar se requiere un mínimo nivel de productividad y que las empresas que exportan tienen en promedio un mayor nivel de productividad que las que no exportan.

22 Una disminución de este umbral si bien incrementaría la muestra de agricultores con capacidad de innovar también reduciría el grado de dicha capacidad y el porcentaje de la muestra se aproximaría a aquella del tamaño de la muestra del factor educativo generando así problemas de colinealidad en las tres ecuaciones como se describe debajo. 
de capacidad se espera que el agricultor pueda incidir en la difusión de las buenas prácticas tecnológicas y la productividad laboral de la unidad productiva. Los signos esperados de los parámetros $\beta_{1 r}$ de E, L, T son positivos y para $D_{G E N}$ y Conex negativos.

Por otro lado, la ecuación [2.2] representa los determinantes de la difusión o uso de la buenas prácticas tecnológicas $\left(D B P_{i r k}^{*}\right)$. Estas comprenden seis variables binarias $D B P_{i r k}$. Estas son la utilización de: semillas certificadas $\left(D B P_{i r 1}\right)$, abonos orgánicos $\left(D B P_{i r 2}\right)$, fertilizantes químicos $\left(D B P_{i r 3}\right)$, insecticidas $\left(D B P_{i r}\right)$, control de plagas $\left(D B P_{i r}\right)$, y certificaciones orgánicas $\left(D B P_{i r}\right)$.

$$
D B P_{i r k}^{*}=\operatorname{Prob}\left(D B P_{i r k}\right)=\alpha_{2 r} \cdot C T I_{i r}^{*}+X_{2 i r} \cdot \beta_{2 r}+\varepsilon_{2 i r} ; k=1,6
$$

Los factores que inciden al uso de estas buenas prácticas son la capacidad tecnológica de innovación $\left(C T I_{i r}^{*}\right)$ (Bell y Paviit, 1993) o el estimado de la probabilidad de que el productor tenga más del $50 \%$ del nivel de capacidad tecnológica de innovación $D_{C T I}^{e}$, y el vector $X_{2 i r}$ de variables las cuales incluyen: la experiencia del productor (jefe de familia), (medido por la variable Edad), la red familiar (medida por el número de miembros de la familia del productor, $\left.N_{F}\right)$, la variable binaria género femenino del productor $\left(D_{G E N}\right)$, y la propiedad de las parcelas cultivadas (Prop, medido por el porcentaje de parcelas cultivadas de propiedad del agricultor). Todas estas variables basadas en los argumentos de Pardey, Alston y Ruttan (2010). Por otro lado, de acuerdo con (Rogers, 1995), las variables distancia geográfica del lugar de producción hacia la capital distrital (Conex, medido en el número de horas que se demora en realizar dicho recorrido) y los posibles efectos derramamientos (spillovers effects) generados por las asociaciones, $\left(D_{A S O}\right)$ influencian también el uso de las buenas prácticas tecnológicas. Aunque la mayoría de los signos teóricos de los parámetros de esta ecuación [2.2] son positivos es posible que en ciertas regiones la relevancia de estos factores sea de signo contrario al esperado de acuerdo a la buena práctica tecnológica usada en dicha región.

Finalmente, la tercera y última ecuación [2.3] corresponde a los determinantes de la productividad laboral de los trabajadores de la unidad productiva $\left(P L_{i r}\right)$.

$$
\ln P L_{i r}=\alpha_{3 r} . C T I_{i r}^{*}+\sum_{k} \gamma_{k r} . D B P_{i r k}^{*}+X_{3 i r} \cdot \beta_{3 r}+\varepsilon_{3 i r} ; i=1, N_{r} ; r=1,23
$$

Donde $\ln$ es el operador logaritmo neperiano y los determinantes incluyen la capacidad tecnológica de innovación, el uso de buenas prácticas tecnológicas y un vector de factores $X_{3 i r}$. Los factores considerados son: el ratio de número de hectáreas usadas por trabajador (T/L), el capital humano del productor medido por el nivel de educación, Edu, la experiencia del productor medido por la variable Edad, la distancia geográfica del lugar de producción hacia la capital de la región, Conex, el grado de diversificación de los cultivos, DCult, medido por el ratio entre el número de cultivos del productor entre el promedio de número de cultivos de la región del productor; la propiedad de las parcelas cultivadas, Pro, medido por el porcentaje de parcelas cultivadas de propiedad 
del agricultor; una variable de los efectos del clima, Clima, propios de las zonas rurales medida por el número de hectáreas de cultivos afectados o destruidos por emergencia (la cual incluye lluvias, vientos fuertes, deslizamientos, incendios, derrumbes, etc.), y la variable binaria género femenino del productor, $D_{G E N}$.

La figura muestra las relaciones especificadas en las tres ecuaciones. Así, la capacidad tecnológica y de innovación influencia el uso y difusión de las buenas prácticas tecnológicas y estos factores inciden sobre la productividad laboral de las unidades productivas de la agricultura comercial moderna (jefes de familia del sector). De acuerdo a la figura y especificaciones descritas, la estrategia de estimación de este sistema no simultáneamente dependiente (donde domina potenciales correlaciones entre las asumidas variables exógenas de las ecuaciones pero que el análisis propuesto predice que dichas correlaciones no altera las propiedades de los estimadores de los métodos de estimación formulados) se basa en la estimación individual de cada ecuación. Específicamente, para la ecuación [2.1], donde las variables que determinan $C T I^{*}$ —asumidas exógenas y por ende no correlacionadas con el error estocástico de la ecuación ${ }^{23}$ son: L, Edu ${ }^{24}, \mathrm{~T}, D_{G E N}$, Conex. Si bien uno de los componentes de $D_{C T I}$ (la variable binaria que reemplaza a $C T I^{*}$ ) es el nivel de educación secundario del jefe de familia y una de las variables 'exógenas' es Edu (capital humano acumulado medido por el nivel de educación), la correlación entre $D_{C T I}$ debido al nivel secundario y Edu probablemente sería baja por varias razones.

Figura 1. Relaciones entre capacidad tecnológica para innovar, difusión de buenas prácticas tecnológicas y productividad laboral

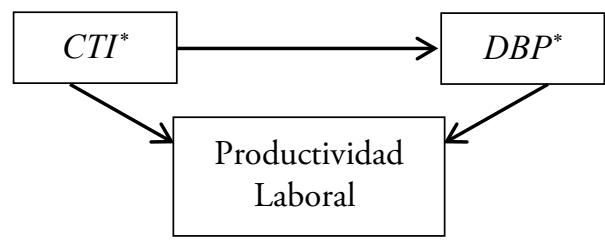

En primer lugar, si los jefes de familia tienen niveles mayor o igual al secundario entonces Djir $=1 / 9=0,11$ es una constante para diferentes valores de Edu (que toma los valores entre 3 y 10). Segundo, de la misma manera aun cuando el jefe de familia tenga nivel mayores al secundario en la medida que $D_{C T I}$ no supere el umbral es $50 \%$ entonces $D_{C T I}$ tomaría el valor constante de cero a pesar de la variabilidad de la variable Edu. Tercero, en la muestra solo el 4,6\% de la muestra de todo el Perú, la variable Djir superó el umbral mientras que el 21,6\% de la muestra tenían niveles de educación mayor o igual al secundario de allí que en $17 \%$ de las observaciones la correlación entre

\footnotetext{
23 Este error captura otros factores no visibles en la determinación de la CTI aunque en promedio se espera que su incidencia en conjunto sea nula.

${ }_{24}$ Note que la variable Edu pretende capturar los factores 'humanos' que inciden en la CTI. Entre otros: el capital humano y la habilidad empresarial y administrativa de los agricultores.
} 
$D_{C T I}$ y EDU sería cero. Por estas razones la ecuación [2.1] se estima con el método Probit con errores estándar 'fuertes o robustos ${ }^{25}$. El coeficiente de Edu en las estimaciones Probit de la ecuación [2.1] representa la contribución del capital humano en la capacidad tecnológica del agricultor en la medida que dicha capacidad exista.

En la ecuación [2.2] las variables asumidas exógenas y que determinan la difusión de buenas prácticas tecnológicas son $\mathrm{CTI}^{*}$ o su proxi el estimado de $D_{C T T}^{e}$, Edad, NF, Conex, $D_{G E N}$, Prop, y $D_{A S O}$. El usar el estimado de la probabilidad de que el agricultor tenga una capacidad e innovación tecnológica, $D_{C T I}^{e}$ que es una variable continua reduce las potenciales correlaciones entre esta probabilidad y la variable binaria $D_{A S O}$. Aun en el hipotético caso que existiese correlación entre estas variables esta potencial colinealidad no afectaría las propiedades de los estimadores. En consecuencia, la ecuación [2.2] también se estima con el método Probit con errores estándar 'fuertes' donde $C T I^{*}$ es reemplaza por la variable $D_{C T I}^{e}$.

Por último, la ecuación [2.3] de la productividad laboral asume como variables 'exógenas' que afectan dicha productividad las variables: $C T I^{*}, D B P^{*}, \mathrm{~T} / \mathrm{L}, D_{\text {Cult }}$, Edad, Edu, $D_{G E N}$, Conex, Clima, y Pro. Al igual que el caso anterior, fuentes de correlaciones existen tanto entre $C T I^{*}$ y $D B P^{*}$ y entre estas variables y el resto de variables. Las colinealidades no afectarían, sin embargo, las propiedades de los estimadores. La variable de la productividad de la tierra T/L puede potencialmente producir sesgos en las estimaciones de la producción en los casos que los productores elijan el tamaño de sus parcelas simultáneamente a su producción. Para los productores de la agricultura moderna de la muestra considerada, está familiar e históricamente determinada para los productores, particularmente para los pequeńos y en consecuencia $\mathrm{T} / \mathrm{L}$ no sería fuente de endogeneidad en la ecuación [2.3]. Otro posible desafío de la estimación de esta ecuación es la construcción de medida de productividad laboral, la cual depende de rendimientos de tierras no necesariamente directamente asociados los productores de la muestra.

De acuerdo a lo anterior, la estrategia de estimación de la ecuación consiste en reemplazar las variables $C T I^{*}$ y $D B P^{*}$ por la variables binarias (no estimadas) $D_{C T I}$ y el conjunto de variables binarias de cada una de las seis buenas prácticas de difusión tecnológica, disminuyendo así las potenciales correlaciones originadas por los estimados de estas variables (usando las ecuaciones [2.1] y [2.2]). Por otro lado, para reducir los problemas de la estimación de la productividad laboral, la ecuación [2.3] se estima con cuatro métodos distintos: mínimos cuadrados ordinarios MCO, el método de cuantiles y los métodos de Probit y Logit ordenados. Los tres últimos métodos usan el orden de los estimados de las productividades laborales y en el caso de los métodos Probit y Logit ordenados dichos estimados se consideran variables latentes y los rangos de productividad se estiman con dichos métodos. El método de cuantiles o específicamente

\footnotetext{
${ }^{25}$ También denominados errores estándar White-Huber o errores estándar heterocedásticos (Stata, 2016).

26 También se estimó la ecuación [2.2] con la variable binaria DCTI. Por razones de espacio dichas estimaciones no son reportadas.
} 
los cuartiles ( $25 \%$ inferior y $75 \%$ o más), por su parte, permite estimar los efectos de las variables independientes sobre la productividad laboral de cada cuartil seleccionado (esto es 25\% inferior y el cuartil superior del 75\%).

Resumiendo, la estrategia econométrica seguida para las estimaciones de las ecuaciones [2.1]-[2.3] $]^{27}$ son las siguientes: las ecuaciones [2.1] y [2.2] se estiman con el método Probit con errores estándar 'fuertes'. La ecuación [2.2] es estimada con la variable binaria $D_{C T I}$ y luego con la estimada probabilidad $D_{C T I}^{e}$ de la estimación [2.1]. Por limitaciones de espacio se reporta esta última estimación. En esta se obtiene los errores estándar mediante las técnicas de bootstrap ${ }^{28}$. La estimación de [2.3] se utilizan cuatro métodos de estimación: mínimos cuadrados ordinarios, regresiones cuantiles del 25\% inferior y el 75\% superior, y los métodos probit y logit ordenados en cuartiles. Los coeficientes probit (P) y marginales (M) de la ecuaciones [2.1] y [2.2] se reportan en los Cuadros 4.1 y 4.2 respectivamente. Los coeficientes de los 4 métodos de estimación de la ecuación [2.3] se reportan en el Cuadro 4.3 para todas las observaciones que se estimaron la productividad laboral ${ }^{29}$. Al igual que el caso de la ecuación [2.2] por razones de espacio en el Cuadro 4.3 solo se reporta las estimaciones de la muestra total para el Perú con la variable $D_{C T I}$. Adicionalmente por las potenciales colinealidades entre la capacidad tecnológica y de innovación y el capital humano ${ }^{30}$, se presenta dos estimaciones en el Cuadro 4.3, una incluyendo la variable capital humano y otra sin incluirla. Cabe finalmente señalar que las variables continuas dependiente e independientes (incluyendo las probabilidades estimadas) de la ecuación [2.3] se transforman en logaritmo natural para interpretar a los respectivos coeficientes como elasticidades. Por las posibles limitaciones de la información usada, los resultados que se muestran a continuación pueden tomarse como hipótesis de trabajo iniciales sobre las relaciones de la Figura $1^{31}$.

\section{DATOS E INDICADORES DE PRODUCTIVIDAD, INNOVACIÓN Y DIFUSIÓN EN LA AGRICULTURA COMERCIAL MODERNA DEL PERÚ, 2012}

La fuente de información para casi todas las variables usadas en las ecuaciones [2.1]-[2.3] es el Censo Nacional Agropecuario de 2012 (INEI-CENAGRO, 2014a). Para los estimados de la productividad laboral, medida por el valor real de producción (base 2007)

\footnotetext{
27 Cabe señalar, que las especificaciones y estimaciones realizadas no buscan encontrar ajustes de regresión altos, sino más bien intentan identificar la relevancia de los factores analizados individualmente y en su conjunto. Los estadísticos (por ejemplo, 2) de las estimaciones indican la relevancia de los factores en su conjunto y dependiendo de la ecuación de factores individuales específicos.

28 Estas técnicas se usan para variables (por ejemplo, las estimadas) donde no se conocen su distribución.

29 Por razones de espacio no se reportan las estimaciones de la productividad laboral para cada uno de las regiones consideradas.

30 Medido por los años de educación acumulados por el jefe de familia.

31 Tello $(2014 \mathrm{a}, 2014 \mathrm{~b})$ ofrece otros métodos alternativos para la estimación de la productividad laboral.
} 
de la unidad productiva por trabajador se utilizaron las siguientes fuentes de datos: MINAGRI (2014), Encuesta Nacional de Programas Estratégicos, INEI-ENAPRES (2014), y la Encuesta Nacional de Hogares 2012 (INEI-ENAHO, 2014). La fuente de emergencias y desastres naturales es de INDECI (2014). La forma como se combinaron estas fuentes se describe a continuación.

La construcción de la variable binaria $D_{\text {CTIir }}$ requirió definir primero a los agricultores jefes de familia netamente agrícolas que producen para el mercado (interno y/o externo). Para ello se consideró un número máximo de animales o aves permitidas tal que el agricultor se especialice en producción agrícola para venta de los mercados nacionales y extranjero ${ }^{32}$. Los agricultores con solo producción de autoconsumo no son considerados en la muestra de las unidades productivas de agricultura comercial moderna. Luego de identificar a estas unidades productivas se calcula la variable binaria en función del promedio de las nueve variables binarias descritas en la sección anterior. El número de unidades productivas de la agricultura comercial moderna que tuvieron información de las variables incluidas en las ecuaciones [2.1] y [2.2] en 2012 fue de $104130^{33}$. Por limitaciones de la muestra de Madre de Dios se combinó las observaciones de esta región con las de la región de Ucayali.

El Cuadro 3.1 describe los porcentajes de unidades productivas: i) que tuvieron información sobre cada uno de los componentes de la CTI, ii) con capacidad tecnológica y de innovación; y iii) que usaron cada una de las seis buenas prácticas tecnológicas ${ }^{34}$. Las cifras de estos indicadores tecnológicos sugieren en primer lugar, solo el 4,6\% de las unidades productivas tenían capacidad tecnológica de innovación. La región que tuvo un mayor proporción de agricultores con capacidad tecnológica de innovar fue Tacna $(18,6 \%)$ y la de menor proporción Huánuco con $0,4 \%$. Segundo, para el Perú y todas sus regiones los componentes que contribuyeron en mayor proporción al CTI fueron la propiedad de las tierras $(74,1 \%)$, el grado de asociación $(36,6 \%)$, la infraestructura productiva $(35,2 \%)$, y la percepción de recibir suficientes ingresos $(29,9 \%)$. Contrariamente, los componentes que en menor proporción incidieron en la CTI fueron la disponibilidad de crédito para compra de capital y herramientas $(0.018 \%)$ y la exportación de productos $(1,4 \%)$. Tercero, el uso de fertilizantes químicos $\left(D B P_{3}\right)$ -con $63,5 \%$ de las unidades productivas, abonos orgánicos $\left(D B P_{2}\right)$-con 62,4\%, y el uso de insecticidas $\left(\mathrm{DBP}_{4}\right)$-con $57,4 \%$ fueron las buenas prácticas tecnológicas con mayor cobertura de uso de las unidades productivas. Contrariamente, solo el 2,7\% de las unidades productivas contaron con certificaciones orgánicas $\left(D B P_{6}\right)^{35}$.

\footnotetext{
32 Estos números no son reportados. En todo caso no superan el valor de 10 de cada una de las especies de crianza del agricultor.

33 La distribución de la muestra por regiones no es reportada.

34 Estos indicadores tecnológicos corresponde a la muestra 104139 unidades productivas.

35 Cabe señalar, que no necesariamente el agricultor requiere usar todas las prácticas tecnológicas. La combinación óptima de estas prácticas, depende entre otras cosas, del paquete tecnológico agrícola usado por el productor. Así, por ejemplo, un agricultor con certificación orgánica es muy raro que "adopte" el uso de fertilizantes o pesticidas.
} 
La productividad laboral, PL, también fue estimada y su construcción comprendió los siguientes pasos:

i) De la base de CENAGRO (INEI-CENAGRO, 2014a) y ENAHO (INEIENAHO, 2014) se identificaron 120 productos agrícolas que se tenía información de precios del productor (soles por $\mathrm{kg}$ ). Para dichos productos se estimaron los precios promedios por distrito de cada región;

ii) De la base de ENAPRES (INEI-ENAPRES, 2014) de 2012 se obtuvo los rendimientos por hectárea de los 120 productos agrícolas. Con estos rendimientos y la extensión de los cultivos de la base de CENAGRO se estimó el volumen de productos (en kg) agrícolas por cada agricultor ${ }^{36}$.

iii) El valor real (base 2007) ${ }^{37}$ de la producción agrícola por trabajador se obtuvo deflactando el valor de producción por trabajador de cada agricultor (o jefe de familia) por el respectivo índice de precio (del sector agropecuario de la región donde se ubica la unidad productiva) obtenido del INEI (2014b).

El Cuadro 3.1 reporta las estimaciones de las PL estimada (base 2007) de la muestra de 76494 unidades productivas. El promedio PL del Perú en 2012 representó el 17\% del PBI per cápita y $87,3 \%$ del estimado de la PL del sector agropecuario para una muestra representativa de 4310 productores reportado en Tello (2014a). Las regiones de menor productividad fueron Apurímac y Huancavelica y las de mayor productividad Tumbes, Moquegua, y Tacna. Este mismo cuadro reporta las probabilidades estimadas de las variables $D_{C T I}$ y de las seis buenas prácticas tecnológicas así como también de las variables inciden en la productividad laboral de la muestra 76494 agricultores comerciales modernos. Las cifras que resaltan del cuadro son:

i) El tamaño de las unidades productivas es relativamente bajo (con promedio de 13 trabajadores y de 2 hectáreas por trabajador por unidad) aunque mayor a la mayoría de productores en el campo, los cuales disponen de menos de cinco hectáreas;

ii) El nivel de educación promedio de todas las observaciones e primaria completa y en promedio $77 \%$ de las parcelas cultivadas son de propiedad del agricultor;

iii) Las emergencias destruyeron en promedio 9 hectáreas de cultivo por distrito de cada región del Perú en 2012.

\footnotetext{
36 En las áreas de terreno donde el productor tenía dos cultivos se dividió en partes iguales la extensión de tierras y se aplicó los rendimientos de los dos cultivos para obtener la producción de ambos productos agrícolas. De otro lado, el promedio nacional de los porcentajes de cultivos que no se dispuso información del total de cultivos de cada productor fue de $22 \%$. Esto implica que las estimaciones del valor real (base 2007 ) de la productividad laboral subestima en $24 \%$ del valor de la producción de los cultivos no incluidos en el cálculo de la productividad.

37 El año de base original es 1994 luego por una regla de tres simple se convirtió los valores a base del año 2007.
} 
Cuadro 3.1. Promedios de indicadores productividad laboral, innovación y difusión tecnológica de unidades productivas de agricultura comercial moderna por regiones, 2012

\begin{tabular}{|c|c|c|c|c|c|c|c|c|c|c|c|c|}
\hline Indicadores & Ama & Anc & Apu & Are & Aya & Caj & Cus & Hua & Huán & Ica & Jun & La-Lib \\
\hline \multicolumn{13}{|c|}{ 1. Capacidad Tecnológica de Innovación $(\%)^{1}$} \\
\hline$D_{E D U}$ & 20,2 & 21,0 & 20,5 & 41,5 & 16,0 & 16,4 & 23,4 & 16,3 & 11,6 & 39,4 & 29,3 & 16,1 \\
\hline$D_{P R O}$ & 86,4 & 62,3 & 53,6 & 69,3 & 75,7 & 85,9 & 55,9 & 71,5 & 76,4 & 66,4 & 67,4 & 75,4 \\
\hline$D_{Y}$ & 31,8 & 26,4 & 21,9 & 24,6 & 25,3 & 27,9 & 20,5 & 31,0 & 30,6 & 26,5 & 31,1 & 38,9 \\
\hline$D_{A S O}$ & 20,3 & 52,5 & 30,0 & 78,4 & 25,7 & 15,9 & 34,4 & 17,1 & 6,3 & 53,2 & 31,6 & 60,2 \\
\hline$D_{A T}$ & 5,5 & 2,8 & 1,9 & 4,5 & 5,8 & 5,5 & 4,8 & 1,1 & 2,9 & 10,0 & 6,8 & 3,5 \\
\hline$D_{T I C}$ & 5,7 & 11,1 & 4,1 & 27,7 & 6,3 & 4,6 & 5,0 & 6,8 & 5,5 & 26,6 & 15,1 & 13,0 \\
\hline$D_{I N F}$ & 11,7 & 22,4 & 53,1 & 74,5 & 44,5 & 8,5 & 40,1 & 31,2 & 4,5 & 83,4 & 27,1 & 41,5 \\
\hline$D_{C R E D}$ & 0,0 & 0,0 & 0,0 & 0,0 & 0,0 & 0,0 & 0,1 & 0,0 & 0,0 & 0,1 & 0,0 & 0,0 \\
\hline$D_{X}$ & 0,1 & 2,1 & 0,2 & 0,9 & 0,4 & 0,5 & 0,3 & 0,1 & 0,2 & 0,5 & 0,4 & 0,5 \\
\hline$C T I$ & 1,8 & 4,0 & 1,3 & 14,8 & 2,1 & 1,4 & 1,0 & 0,8 & 0,4 & 12,4 & 3,7 & 7,1 \\
\hline \multicolumn{13}{|c|}{ 2. Buenas Prácticas Tecnológicas $(\mathrm{BP}, \%)^{1}$} \\
\hline$D_{B P 1}$ & 16,4 & 20,8 & 6,2 & 41,5 & 11,7 & 8,8 & 7,9 & 5,3 & 11,7 & 67,7 & 13,6 & 28,1 \\
\hline$D_{B P 2}$ & 43,1 & 84,3 & 86,7 & 75,8 & 73,6 & 55,5 & 75,0 & 91,9 & 73,2 & 76,9 & 68,1 & 75,8 \\
\hline$D_{B P 3}$ & 30,5 & 89,1 & 66,8 & 78,5 & 61,6 & 48,1 & 59,6 & 69,6 & 71,3 & 87,4 & 61,5 & 90,4 \\
\hline$D_{B P 4}$ & 29,6 & 79,9 & 64,8 & 77,3 & 61,6 & 32,3 & 43,6 & 52,6 & 70,7 & 88,6 & 52,8 & 87,0 \\
\hline$D_{B P 5}$ & 6,8 & 6,9 & 9,0 & 10,7 & 7,4 & 8,2 & 6,9 & 4,0 & 5,8 & 18,4 & 6,0 & 4,4 \\
\hline$D_{B P 6}$ & 4,1 & 0,8 & 0,5 & 1,3 & 1,0 & 3,2 & 1,9 & 0,2 & 1,0 & & 3,1 & 0,6 \\
\hline \multicolumn{13}{|c|}{ 3. Productividad Laboral, CTI, BP, Determinantes ${ }^{3}$} \\
\hline $\mathrm{PL}^{2}$ & 1034,3 & 1443,3 & 469,2 & 984,7 & 952,0 & 2084,9 & 2233,3 & 604,5 & 3055,2 & 2048,9 & 4117,7 & 1635,7 \\
\hline $\mathrm{L}$ & 22,10 & 5,97 & 14,92 & 41,24 & 17,85 & 15,40 & 16,18 & 11,06 & 5,85 & 44,02 & 5,51 & 9,46 \\
\hline $\mathrm{T} / \mathrm{L}$ (ha & & 1,38 & 0,60 & 0,67 & 1,13 & 1,24 & 2,37 & 0,93 & 3,45 & 1,30 & 3,42 & 2,16 \\
\hline $\mathrm{T}$ & 12,32 & 4,18 & 3,82 & 5,58 & 6,20 & 6,74 & 9,47 & 4,58 & 10,18 & 9,04 & 10,83 & 7,05 \\
\hline DCult & 1,03 & 1,25 & 0,99 & 1,06 & 1,05 & 1,09 & 1,08 & 1,16 & 0,95 & 1,08 & 1,08 & 1,25 \\
\hline Edad & 45,80 & 54,16 & 46,39 & 56,79 & 45,92 & 45,56 & 49,78 & 47,51 & 43,36 & 57,05 & 45,88 & 52,32 \\
\hline Edu & 4,12 & 3,75 & 3,68 & 5,04 & 3,77 & 3,83 & 3,92 & 3,72 & 3,46 & 4,89 & 4,48 & 3,58 \\
\hline$D_{G E N}(\%)$ & 16,4 & 32,2 & 29,0 & 32,2 & 31,5 & 25,3 & 33,0 & 28,6 & 0,0 & 27,8 & 29,3 & 24,9 \\
\hline Conex & 1,85 & 0,79 & 1,10 & 0,22 & 1,29 & 1,94 & 1,68 & 1,52 & 1,82 & 0,20 & 1,33 & 2,03 \\
\hline Pro (\%) & 88,6 & 64,1 & 54,0 & 71,7 & 77,2 & 88,4 & 63,3 & 70,9 & 76,2 & 69,1 & 69,4 & 79,4 \\
\hline Clima (ha/E) & 0,18 & 0,06 & 0,04 & 21,28 & 0,00 & 0,32 & 25,50 & 5,78 & 1,42 & 3,25 & 0,92 & 0,05 \\
\hline
\end{tabular}

Fuente: INEI-CENAGRO (2014a). Elaboración propia. ${ }^{1}$ Muestra de 104130 unidades de producción. ${ }^{2}$ En soles de 2007 por trabajador. ${ }^{3}$ Muestra de 76494 unidades de producción. Los niveles de educación varían entre ningún nivel (1) hasta el nivel posgrado (10). El nivel promedio es primaria completa (4). 
Cuadro 3.1. Promedios de indicadores productividad laboral, innovación y difusión tecnológica de unidades productivas de agricultura comercial moderna por regiones, 2012

\begin{tabular}{|c|c|c|c|c|c|c|c|c|c|c|c|c|}
\hline Indicadores & Lam & $\mathrm{L}-\mathrm{C}$ & Lor & Moq & Pas & Piu & Pun & San & Tac & Tum & UcaMd & Perú \\
\hline \multicolumn{13}{|c|}{ 1. Capacidad Tecnológica de Innovación (\%) } \\
\hline$D_{E D U}$ & 18,1 & 37,8 & 25,5 & 38,2 & 34,1 & 15,4 & 24,8 & 15,7 & 45,7 & 32,3 & 29,1 & 21,6 \\
\hline$D_{P R O}$ & 73,8 & 59,7 & 57,8 & 89,9 & 40,3 & 80,8 & 91,0 & 81,8 & 66,0 & 78,3 & 62,5 & 74,1 \\
\hline$D_{Y}$ & 27,1 & 36,4 & 31,4 & 24,0 & 30,0 & 29,2 & 22,0 & 43,1 & 33,6 & 36,4 & 35,5 & 29,9 \\
\hline$D_{A S O}$ & 82,5 & 66,5 & 8,9 & 23,6 & 9,3 & 58,2 & 17,3 & 15,2 & 75,2 & 61,2 & 27,6 & 36,6 \\
\hline$D_{A T}$ & 2,7 & 7,9 & 2,4 & 9,9 & 5,4 & 7,6 & 4,6 & 7,3 & 12,7 & 7,1 & 11,6 & 5,5 \\
\hline$D_{T I C}$ & 13,9 & 29,2 & 7,9 & 19,0 & 16,6 & 19,2 & 7,7 & 8,8 & 32,7 & 31,3 & 7,9 & 12,1 \\
\hline$D_{I N F}$ & 88,2 & 46,8 & 1,2 & 28,5 & 3,5 & 56,3 & 56,7 & 10,0 & 57,1 & 53,8 & 4,4 & 35,2 \\
\hline$D_{C R E D}$ & 0,0 & 0,0 & 0,1 & 0,0 & 0,1 & 0,0 & 0,0 & 0,0 & 0,1 & 0,2 & 0,0 & 0,0 \\
\hline$D_{X}$ & 0,6 & 1,0 & 1,1 & 2,0 & 0,5 & 5,8 & 7,9 & 0,3 & 4,4 & 4,7 & 0,1 & 1,4 \\
\hline$C T I$ & 6,9 & 10,8 & 0,8 & 5,6 & 1,6 & 9,7 & 3,0 & 2,1 & 18,6 & 13,1 & 1,9 & 4,6 \\
\hline \multicolumn{13}{|c|}{ 2. Buenas Prácticas Tecnológicas (BP, \%) } \\
\hline$D B P_{1}$ & 59,1 & 44,4 & 16,4 & 25,5 & 8,5 & 42,1 & 5,5 & 18,8 & 30,4 & 52,9 & 20,7 & 22,6 \\
\hline$D B P_{2}$ & 42,8 & 90,9 & 8,7 & 88,8 & 75,0 & 47,5 & 80,0 & 18,8 & 86,1 & 38,8 & 26,5 & 62,4 \\
\hline $\mathrm{DBP}_{3}$ & 87,9 & 86,4 & 12,6 & 67,2 & 75,1 & 74,7 & 49,7 & 26,7 & 90,5 & 85,7 & 27,6 & 63,5 \\
\hline $\mathrm{DBP}_{4}$ & 88,2 & 85,6 & 16,3 & 68,9 & 65,1 & 71,6 & 49,7 & 25,6 & 78,2 & 65,4 & 27,9 & 57,4 \\
\hline$D B P_{5}$ & 6,0 & 9,2 & 6,9 & 13,6 & 5,6 & 12,3 & 4,0 & 6,3 & 18,8 & 7,2 & 3,1 & 7,8 \\
\hline$D B P_{6}$ & 1,7 & 0,8 & 1,7 & 2,8 & 1,9 & 6,7 & 5,4 & 2,9 & 0,9 & 6,9 & 3,3 & 2,7 \\
\hline \multicolumn{13}{|c|}{ 3. Productividad Laboral, CTI, BP, Determinantes } \\
\hline $\mathrm{PL}^{1}$ & 618,0 & 938,5 & 2314,2 & 5220,2 & 1909,0 & 4198,2 & 2568,8 & 2838,9 & 5015,9 & 9279,1 & 4322,5 & 2423,9 \\
\hline $\mathrm{L}$ & 11,21 & 23,87 & 9,74 & 6,99 & 6,74 & 5,62 & 3,85 & 16,04 & 11,07 & 22,60 & 4,39 & 13,43 \\
\hline T/L (has/trab) & 1,70 & 0,94 & 4,20 & 1,06 & 4,60 & 1,88 & 2,45 & 3,15 & 5,93 & 1,23 & 18,68 & 2,24 \\
\hline $\mathrm{T}$ & 7,89 & 5,82 & 22,34 & 3,90 & 13,54 & 5,45 & 6,72 & 15,67 & 13,51 & 5,23 & 44,46 & 8,78 \\
\hline DCult & 1,08 & 1,28 & 1,21 & 1,25 & 1,02 & 1,16 & 1,65 & 0,99 & 1,38 & 1,02 & 1,14 & 1,11 \\
\hline Edad & 56,83 & 57,17 & 41,55 & 53,17 & 41,92 & 55,74 & 51,62 & 42,07 & 50,52 & 54,96 & 40,89 & 48,85 \\
\hline Edu & 3,82 & 4,96 & 4,57 & 4,94 & 4,71 & 3,59 & 4,11 & 4,05 & 5,24 & 4,53 & 4,68 & 4,03 \\
\hline$D_{G E N}(\%)$ & 30,8 & 32,7 & 0,0 & 35,1 & 27,1 & 18,2 & 34,9 & 14,0 & 33,4 & 16,8 & 20,9 & 24,6 \\
\hline Conex & 0,35 & 0,51 & 3,58 & 0,80 & 1,70 & 0,81 & 1,29 & 1,64 & 0,64 & 0,19 & 2,48 & 1,36 \\
\hline Pro (\%) & 77,5 & 66,0 & 59,9 & 90,5 & 38,3 & 81,7 & 92,4 & 84,4 & 65,9 & 79,0 & 64,6 & 77,0 \\
\hline Clima (ha/E) & 6,67 & 1,62 & 82,03 & 5,93 & 148,92 & 11,48 & 1,54 & 28,48 & 0,00 & 39,25 & 0,00 & 9,60 \\
\hline
\end{tabular}

Fuente: INEI-CENAGRO (2014a). Elaboración propia. ${ }^{1}$ Muestra de 104130 unidades productivas. ${ }^{2}$ En soles de 2007 por trabajador. ${ }^{3}$ Muestra de 76494 unidades productivas. Los niveles de educación varían entre ningún nivel (1) hasta el nivel posgrado (10). El nivel promedio es primaria completa (4). 


\section{ESTIMACIONES Y RESULTADOS}

Las cifras del Cuadro 4.1, que muestran las estimaciones de la ecuación [2.1], indican que para las 104130 observaciones del Perú, el tamaño (en trabajadores y en extensión de tierras) de las unidades productivas, el capital humano acumulado por el productor $\mathrm{y}$ la distancia geográfica (del centro de producción a la capital del distrito de la ubicación del centro) incidieron de manera estadísticamente significativa en la capacidad tecnológica y de innovación de los productores de la agricultura comercial moderna. En el caso de la educación es obvio que incide en dicha capacidad. El resultado del efecto positivo y estadísticamente significativo del coeficiente del tamaño de la unidad agrícola, sugiere que este 'incentiva' o 'impone' una valla más alta a los agricultores para explotar las tierras y por ende exige una mayor capacidad tecnológica para realizar dicha explotación. Contrariamente, en la medida que métodos tradicionales (heredados o imitados) de producción son usados por minifundistas (o productores de tamaños pequeños de tierras y/o de empleo de trabajadores) la necesidad de una capacidad tecnológica puede no ser alta. De otro lado, la lejanía del centro de producción de la capital del distrito al parecer ha influenciado de forma negativa a la capacidad tecnológica y de innovación dado que el efecto de 'derrame' (spillover) de la información de la capital de distrito tiende a desaparecer en la medida que el centro de producción se aleja de dicha capital. Finalmente, la capacidad tecnológica y de innovación diverge por el género del jefe de familia de la unidad productiva. Los jefes de familia mujeres tienen una menor probabilidad de disponer de dicha capacidad que los jefes de familia hombres.

La presentación de los resultados a nivel de regiones puede ser hecha de diversas maneras ${ }^{38}$. Sin embargo, para fines de información de las propias regiones y para la capacidad de innovar y la difusión de las buenas prácticas tecnológicas se presentan los resultados econométricos de todas las regiones. Para la ecuación de productividad solo se presenta los resultados para el agregado de regiones. Los resultados completos son presentados en el informe final en que se basa el presente estudio. Como era de esperarse los signos y relevancia estadística de los coeficientes de las estimaciones fueron diversos o heterogéneos ${ }^{39}$. En 13 de 23 regiones, el coeficiente del tamaño en número de trabajadores fue estadísticamente positivo y significativo. El mismo resultado de los coeficientes se obtuvo en 11 de 23 regiones para el tamaño en extensión de tierras. El coeficiente del capital humano fue estadísticamente significativo y positivo para todas las regiones del Perú. En 11 de 23 regiones las distancias geográficamente lejanas o de menor infraestructura vial afectaron negativa y significativamente a la capacidad tecnológica

\footnotetext{
38 Por ejemplo: mapas, colores, grupos de coeficientes etc.

39 Las regresiones regionales no buscan explicar la heterogeneidad de las mismas sino mostrar que, bajo el actual proceso de descentralización (donde los departamentos se convirtieron en regiones) políticas horizontales y a nivel nacional no necesariamente tendrán los mismos efectos para todas las regiones por las diferencias en los efectos de las variables determinantes de la capacidad tecnológica, uso de buenas prácticas tecnológicas y la productividad laboral de las unidades del sector agrícola moderno.
} 
de innovación de las unidades productivas. El efecto de brecha de género fue estadísticamente significativo en 8 de las 22 regiones que se dispuso de información de la brecha de género ${ }^{40}$.

Los coeficientes estimados de la ecuación [2.2] mostrados en los Cuadros 4.2 indican que la capacidad tecnológica y de innovación y los potenciales efectos derramamientos originados por las asociaciones de agricultores fueron factores determinantes y estadísticamente significativos para prácticamente la totalidad de las buenas prácticas tecnológicas de los 104130 agricultores del Perú ${ }^{41}$. Los efectos del resto de variables fueron diversos.

Las variables de experiencia del agricultor (representada por la edad del mismo) y la red familiar (representada por la variable proxi el número de miembros de la familia) incidieron de forma estadísticamente significativa y positiva para la mayoría de las buenas prácticas tecnológicas ${ }^{42}$. Los contrarios efectos fueron producidos por las distancias geográficas lejanas y la proporción de parcelas de propiedad del agricultor, también para la mayoría de las buenas prácticas tecnológicas ${ }^{43}$. Si bien los efectos de la información resultante de la cercanía a las capitales de distrito, inciden en una mayor probabilidad del uso de las buenas prácticas tecnológicas, los agricultores con un mayor grado de propiedad de sus parcelas resultan tener una menor probabilidad de usar dichas buenas prácticas. Esto sugiere que las decisiones del uso de estas prácticas de forma directa del agricultor se incrementan con el mayor grado de propiedad de las parcelas y en consecuencia el nivel educativo y experiencia del agricultor inciden en mayor proporción en dichas decisiones.

\footnotetext{
40 En la región Huánuco todos los jefes de familia de la muestra fueron hombres.

${ }^{41}$ La excepción fue la sexta práctica referente a certificaciones orgánicas. Sin embargo, también para esta práctica los coeficientes de la CTI y la asociatividad fueron estadísticamente significativos cuando se usa la variable binaria $D_{C T I}$ en lugar de la estimada probabilidad $D_{C T I}^{e}$. Este resultado no se reporta por razones de espacio. ${ }^{42}$ Las excepciones fueron el uso de control de plagas $\left(D B P_{5}\right)$ y certificaciones $\left(D B P_{6}\right)$ para la variable experiencia y uso de abonos (DBP2) para el caso del número de miembros de la familia.

43 Las excepciones fueron el uso certificaciones $\left(D B P_{6}\right)$ para la variable conexiones y control de plagas $\left(D B P_{5}\right)$ y certificaciones $\left(D B P_{6}\right)$ para la propiedad de parcelas de los agricultores. Cabe además señalar, que las variables de experiencia y red familiar pueden tener efectos no lineales sobre la difusión de las buenas prácticas tecnológicas. Así, puede existir niveles óptimos de estas variables en los cuales valores menores a estos niveles, los efectos de estas variables serán positivos y a valores mayores a dicho niveles los efectos serían negativos.
} 


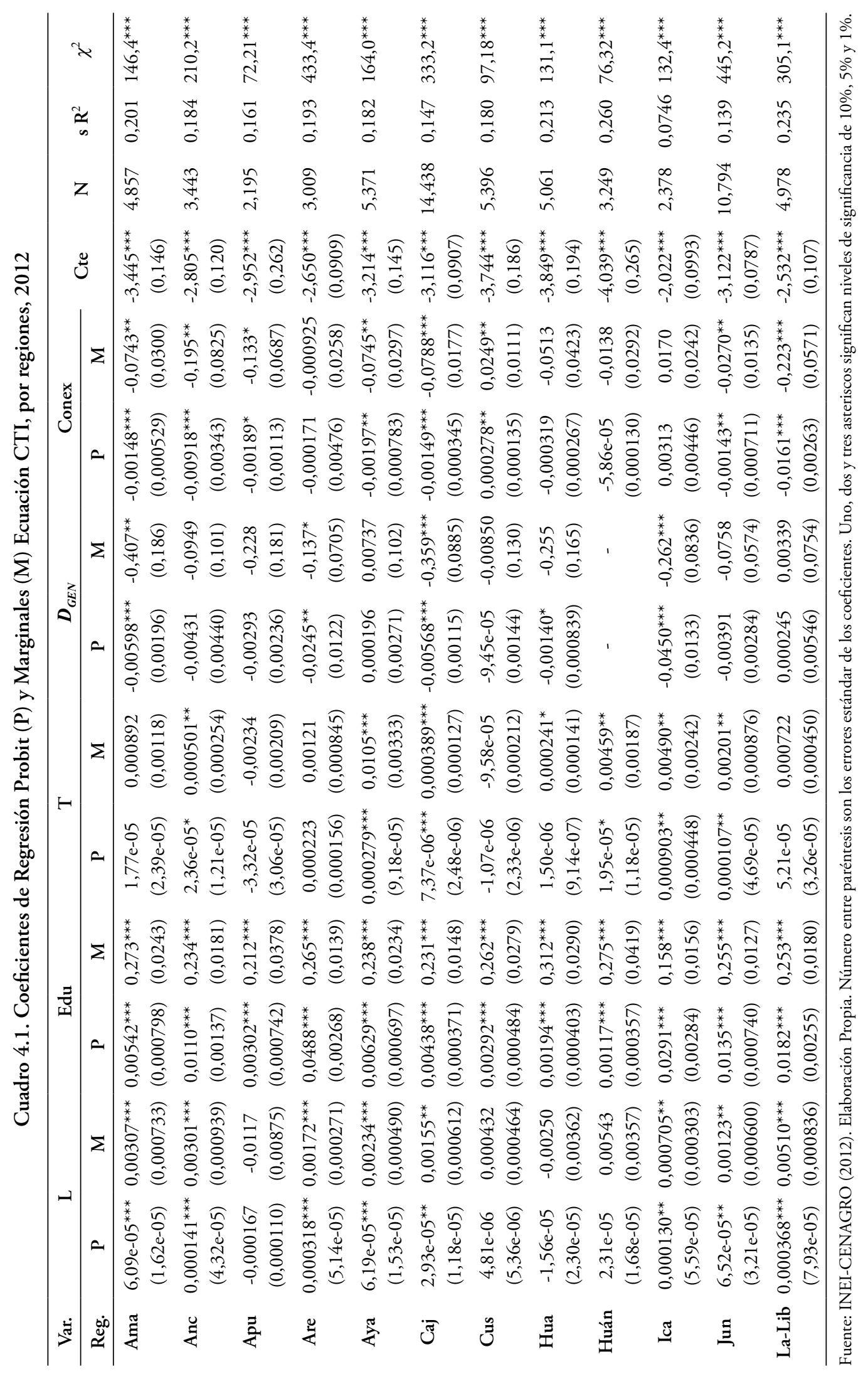




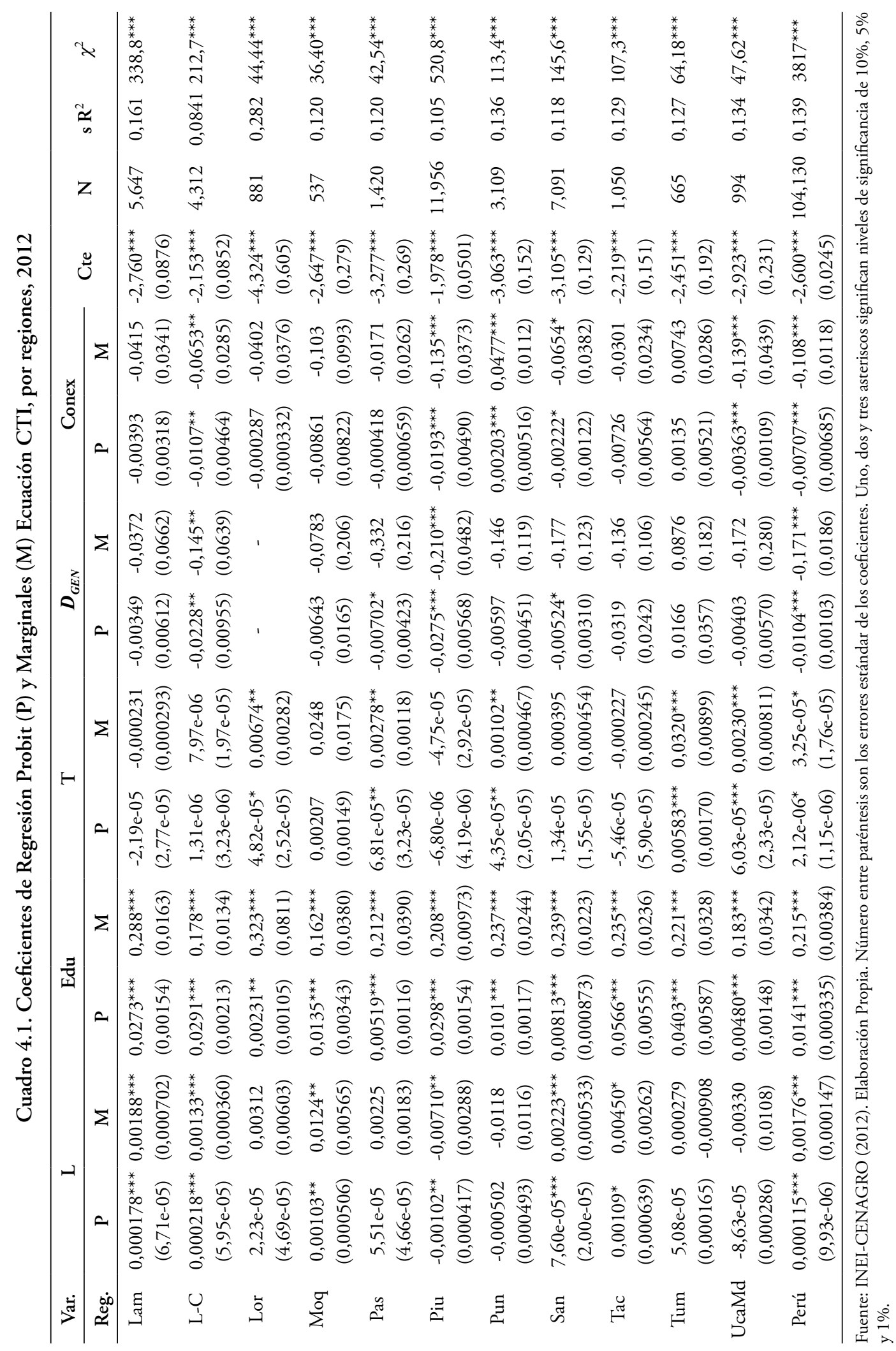




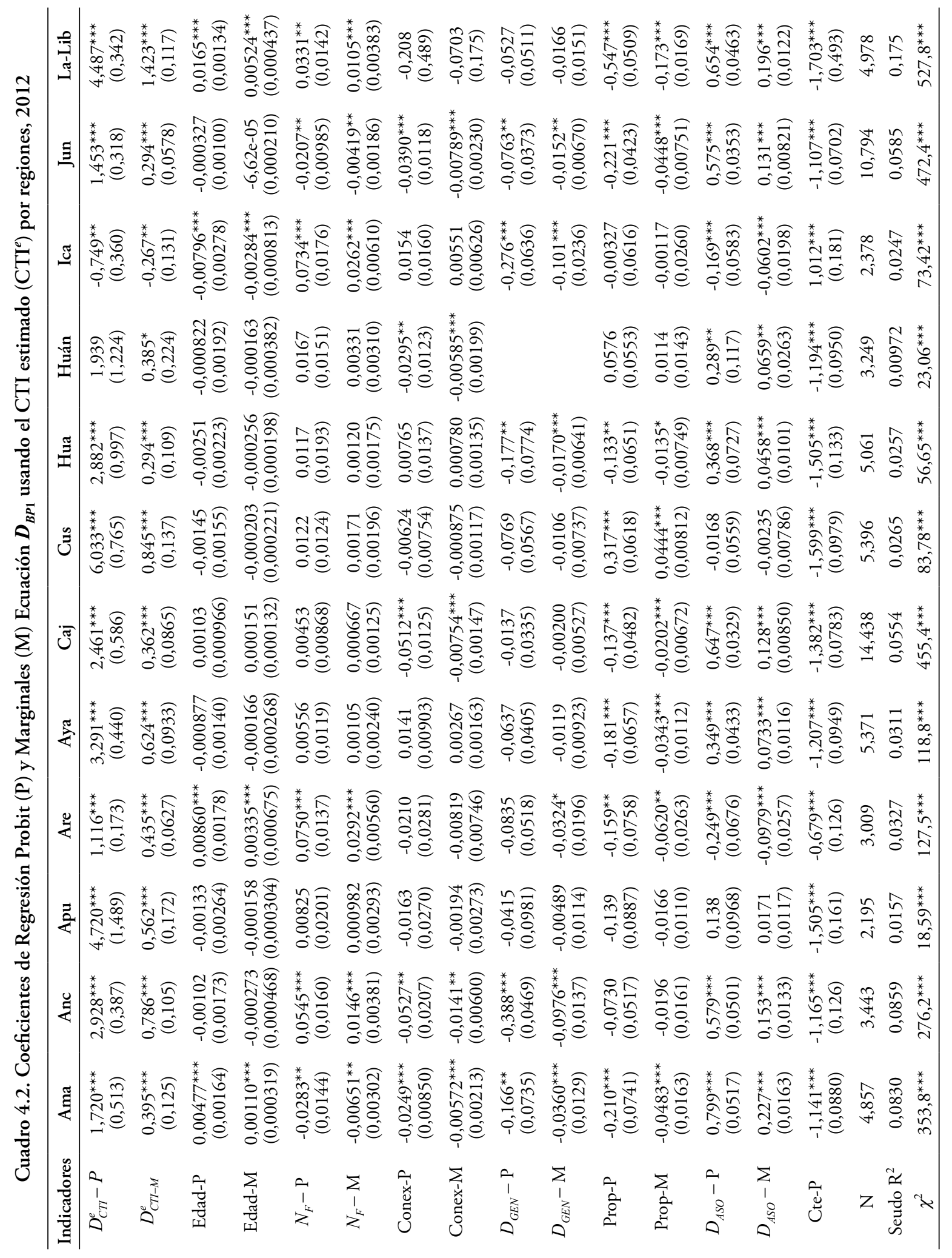




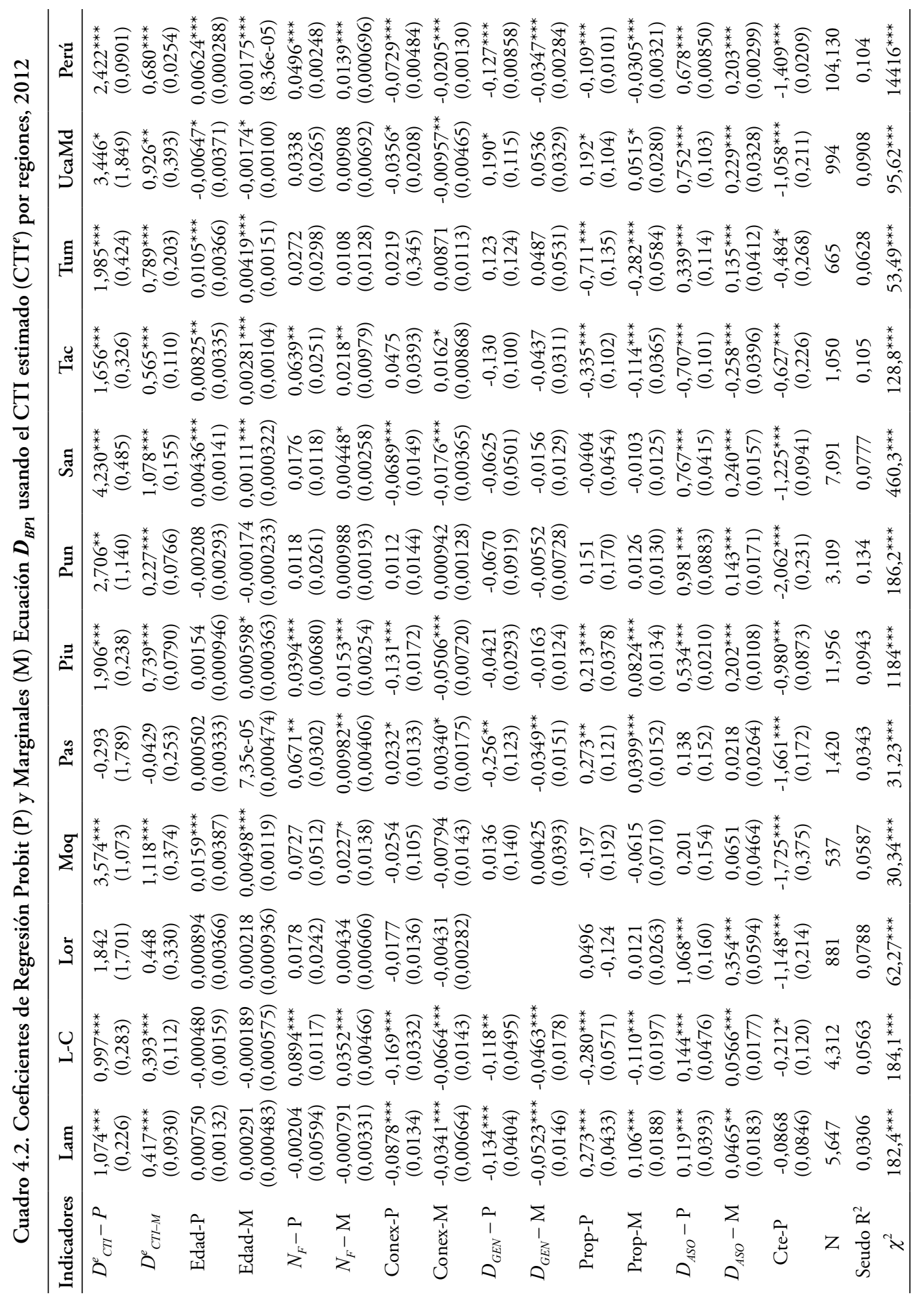




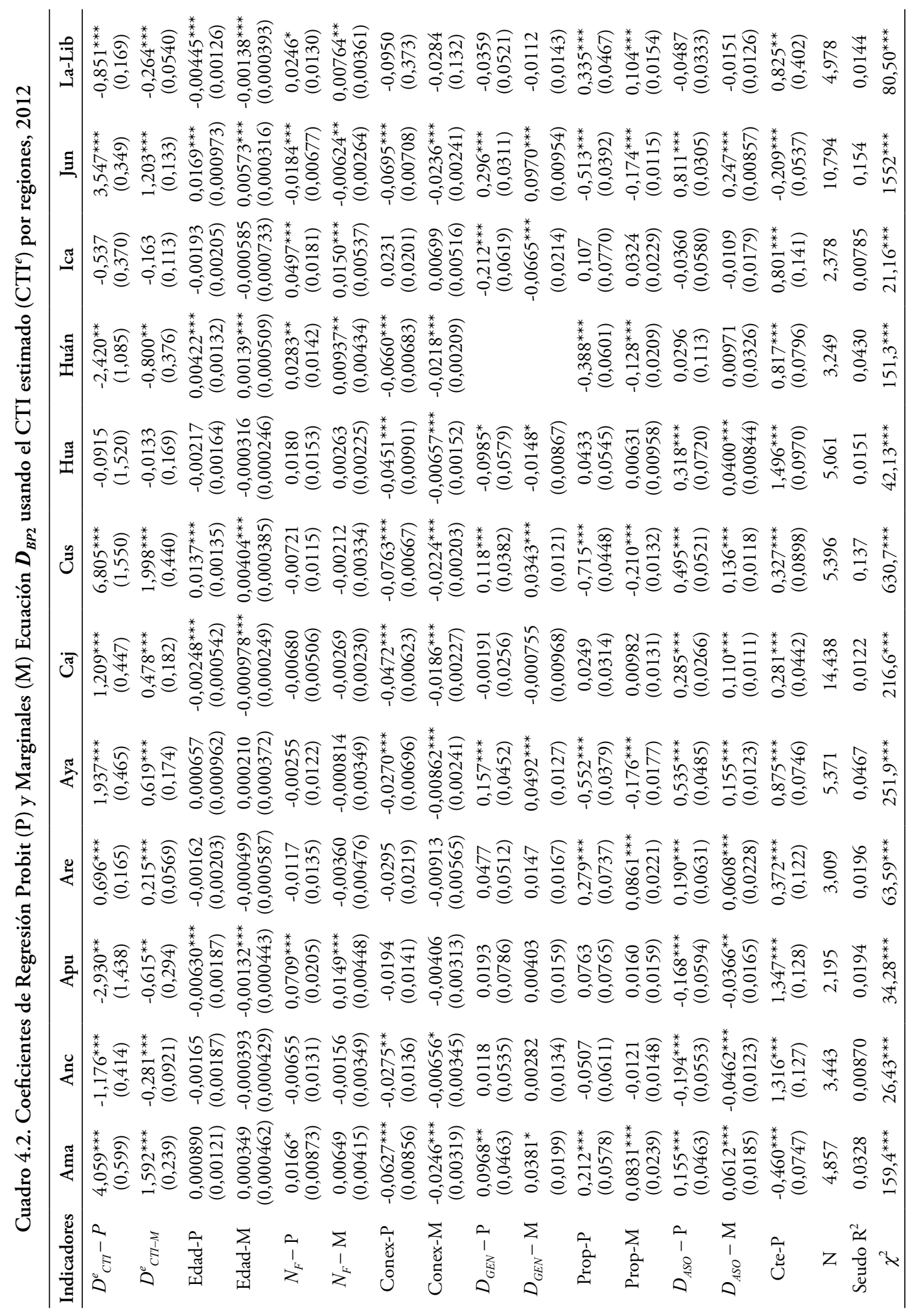




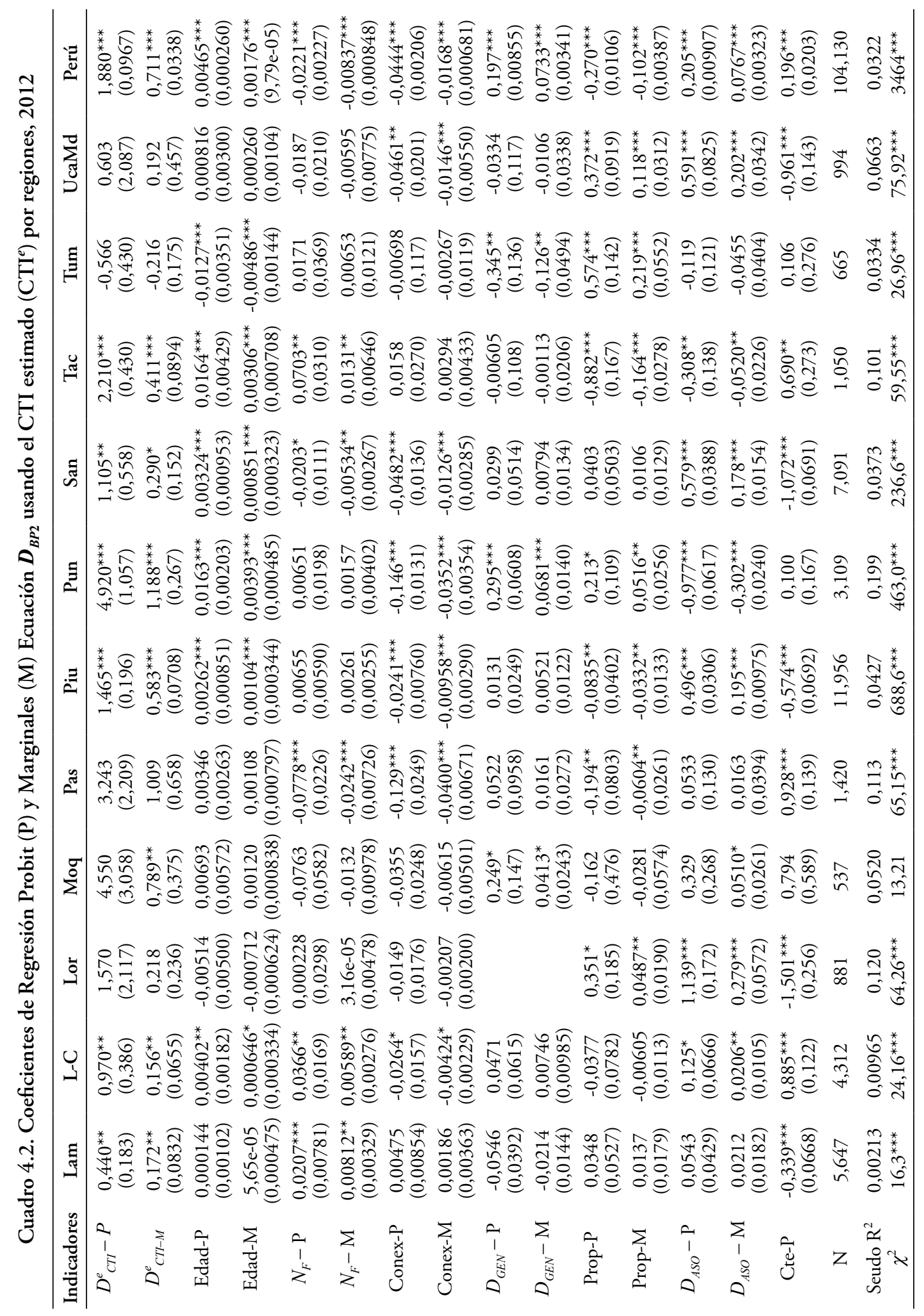




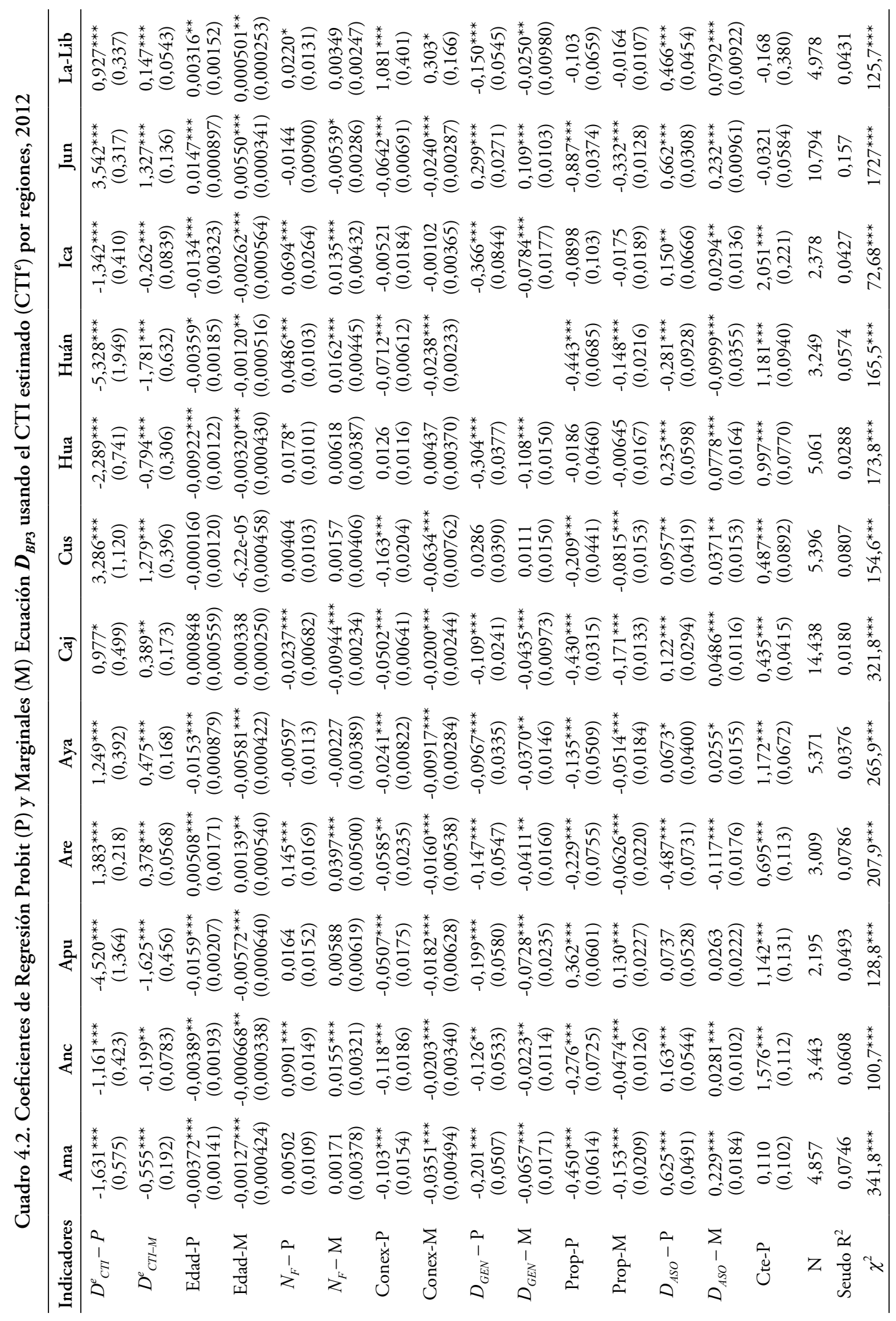




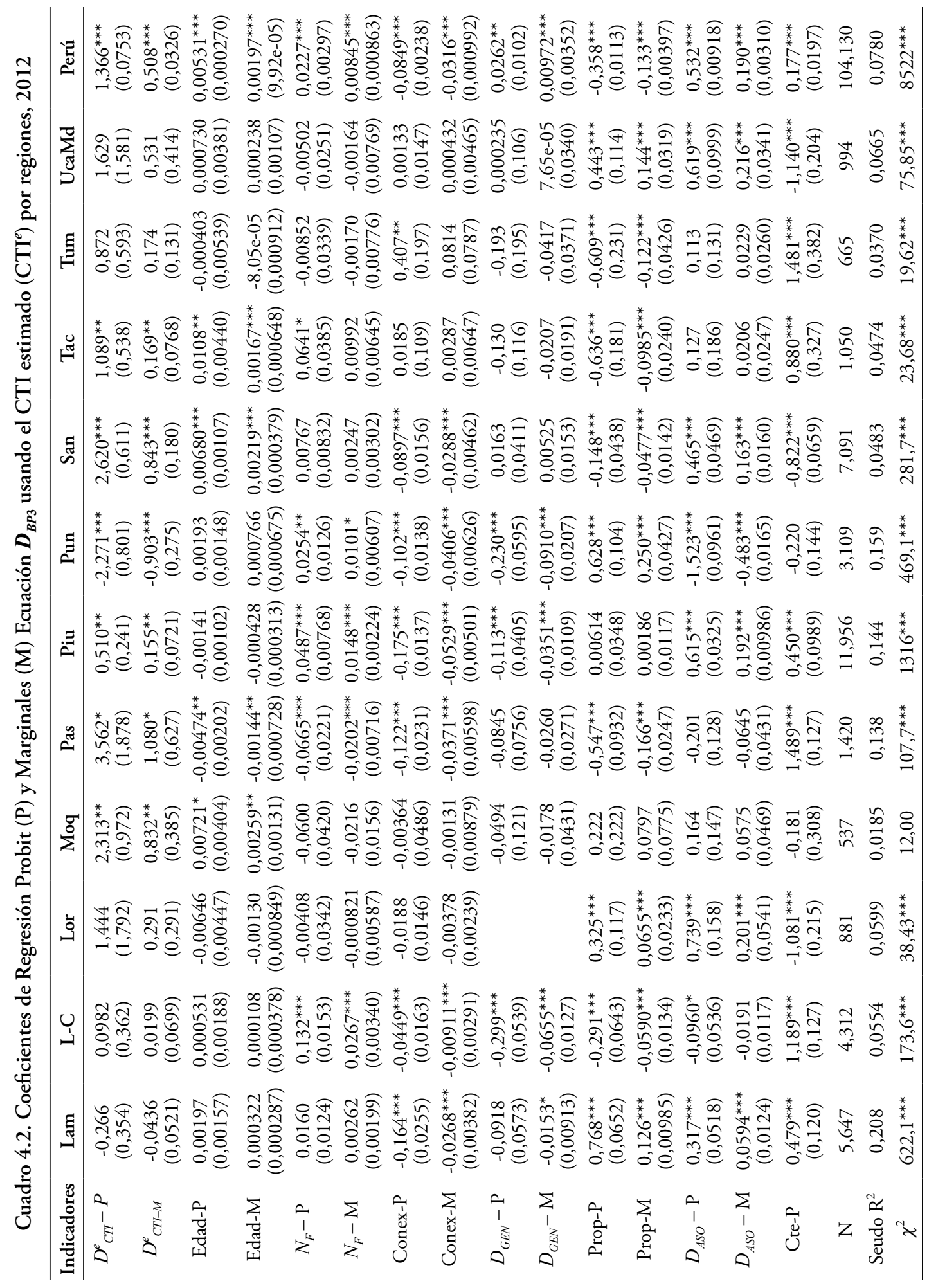




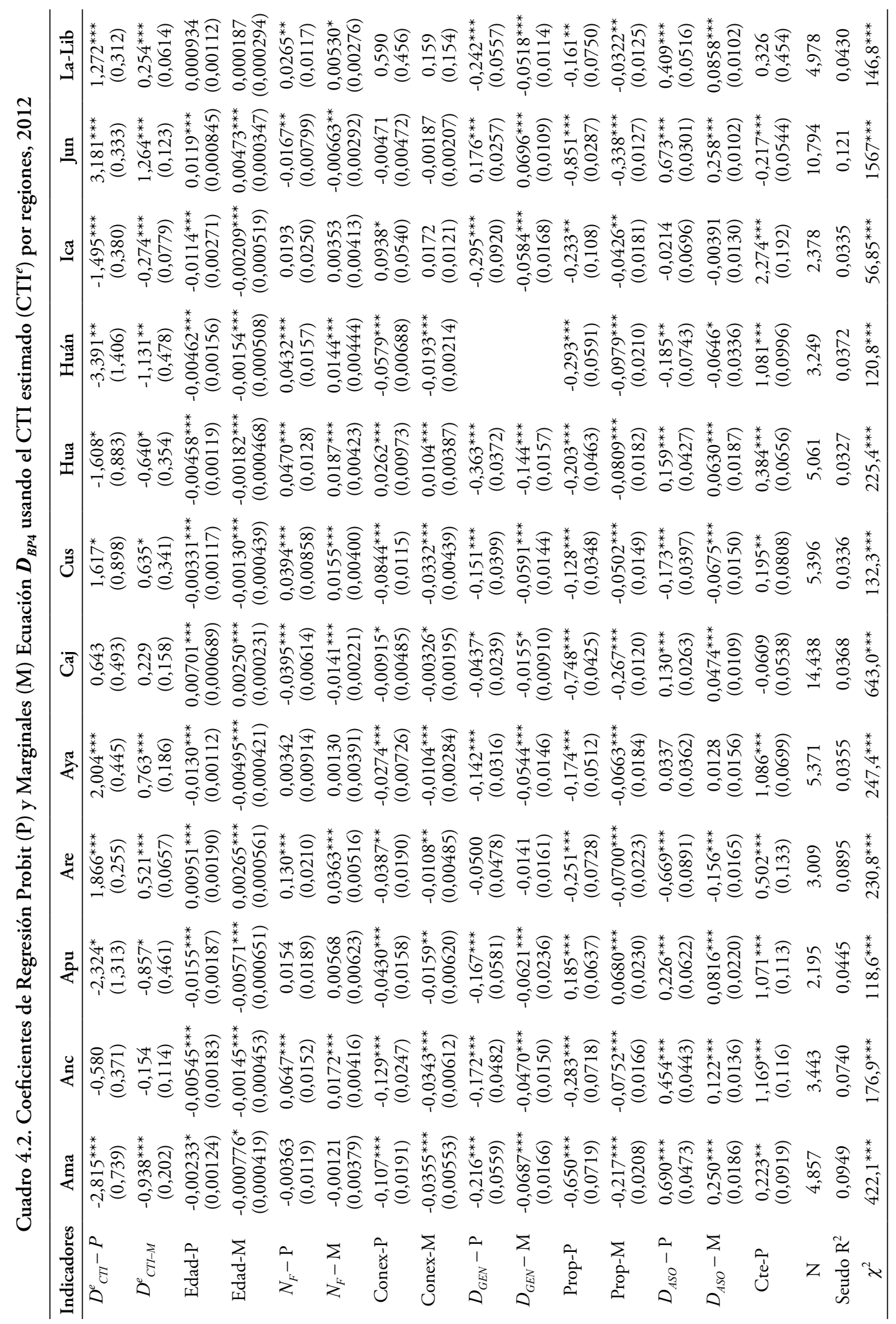




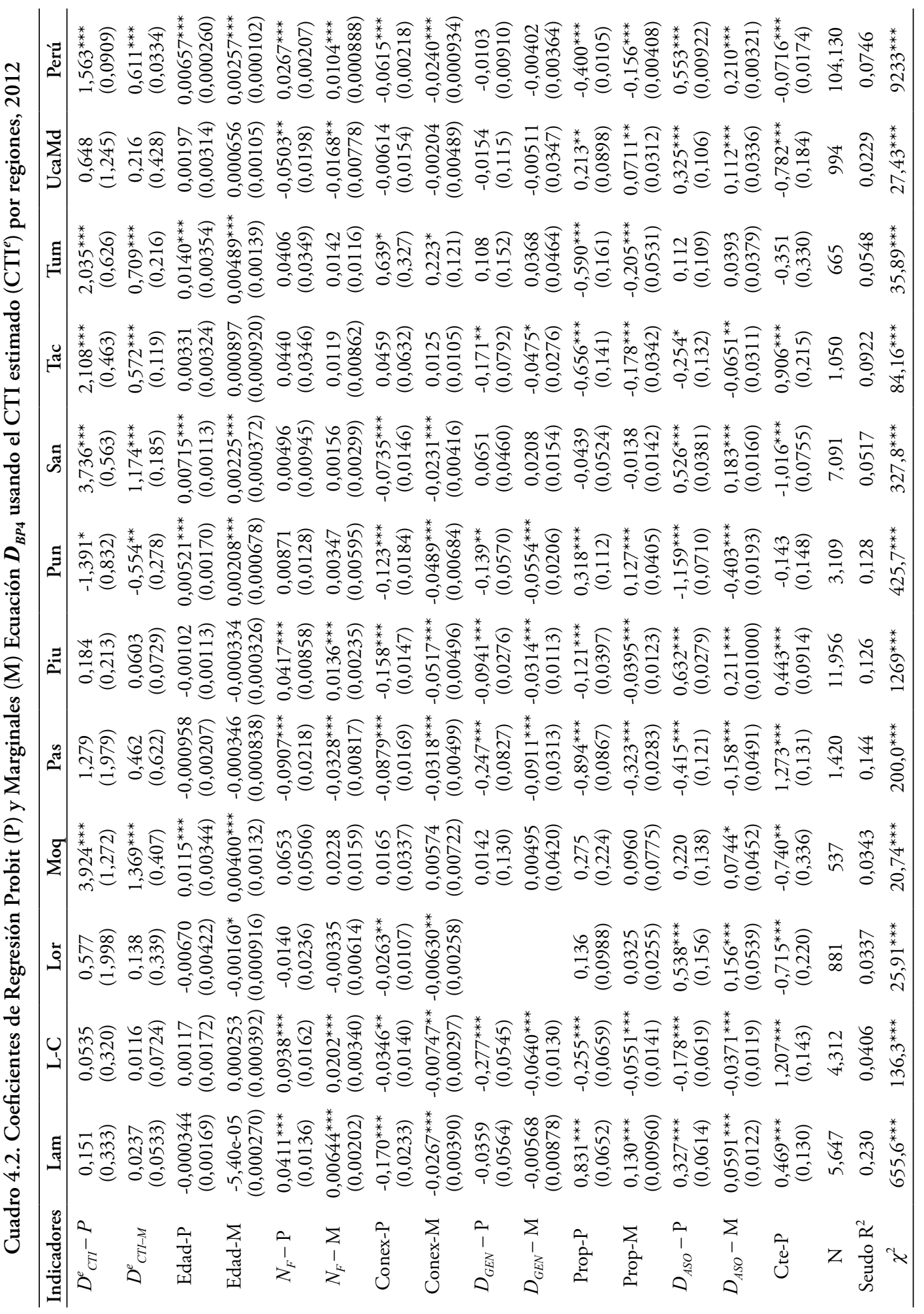




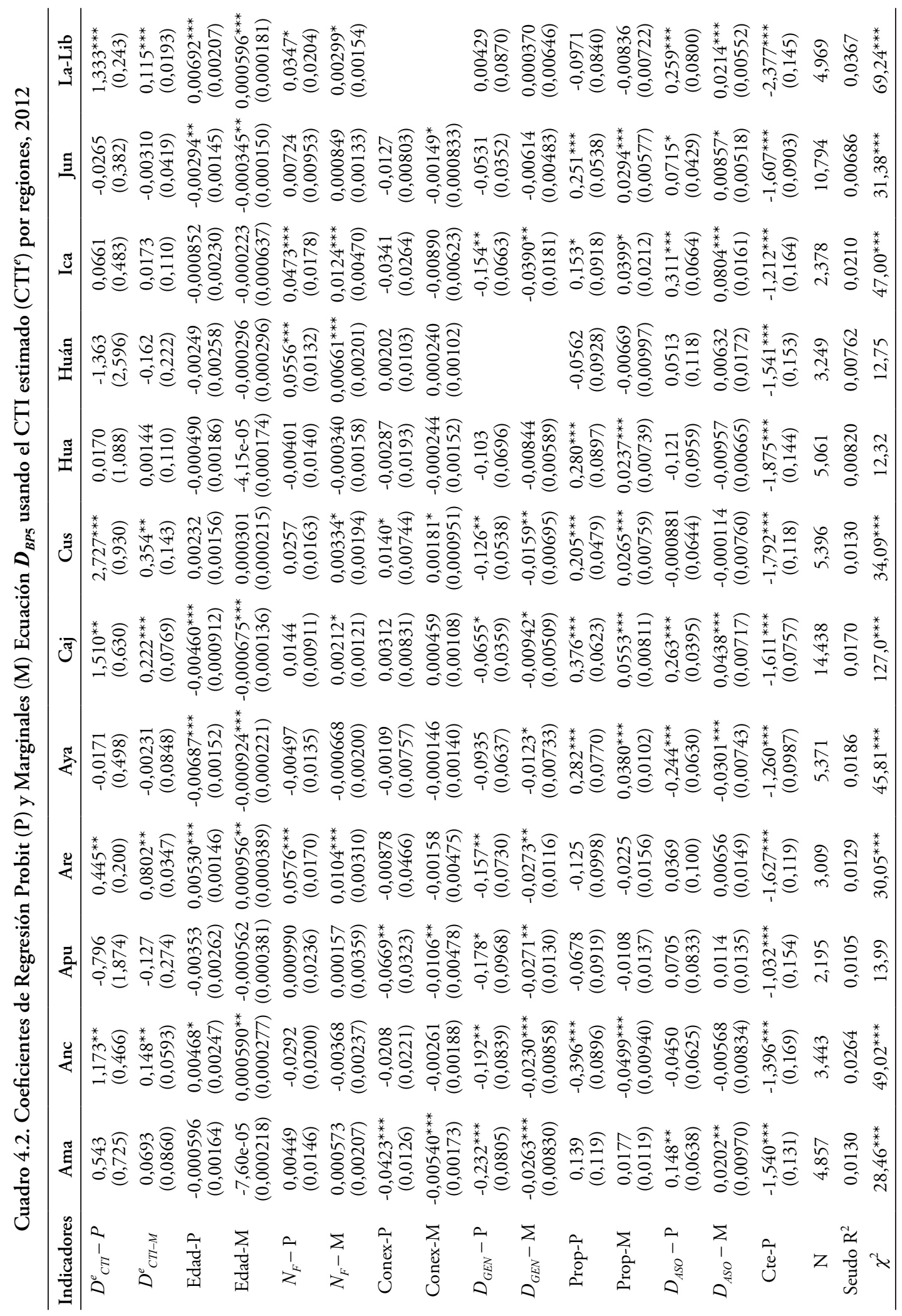




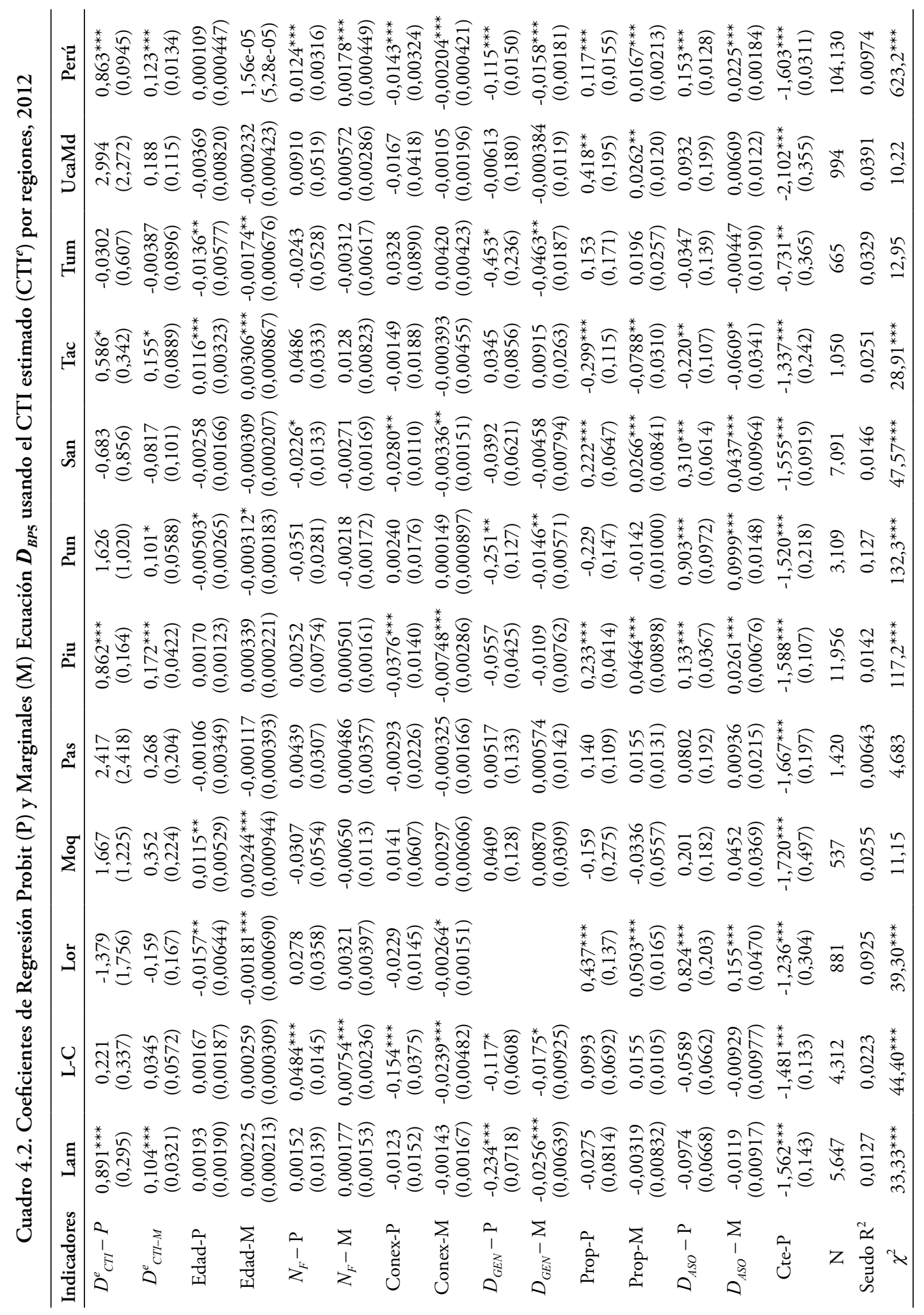




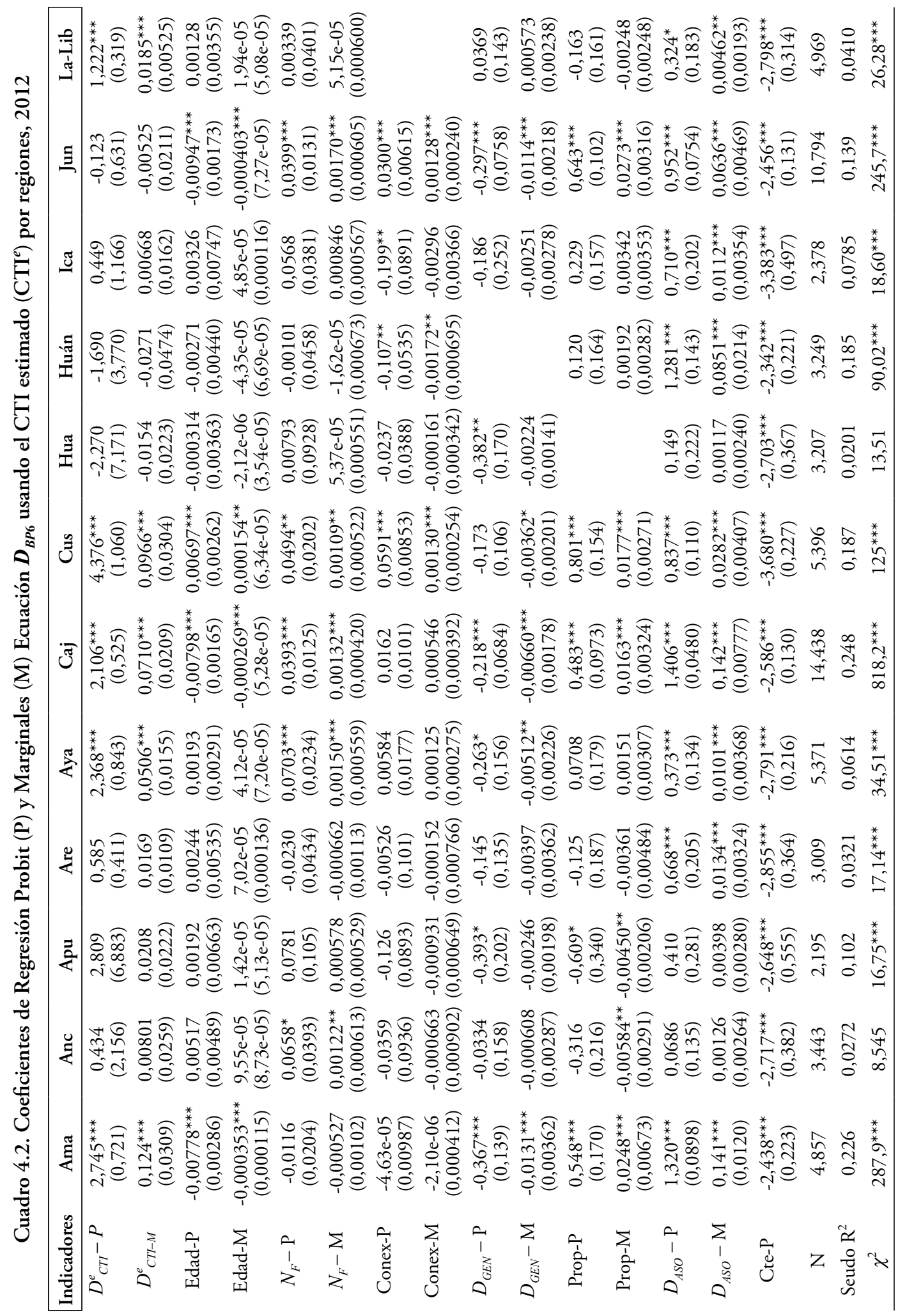




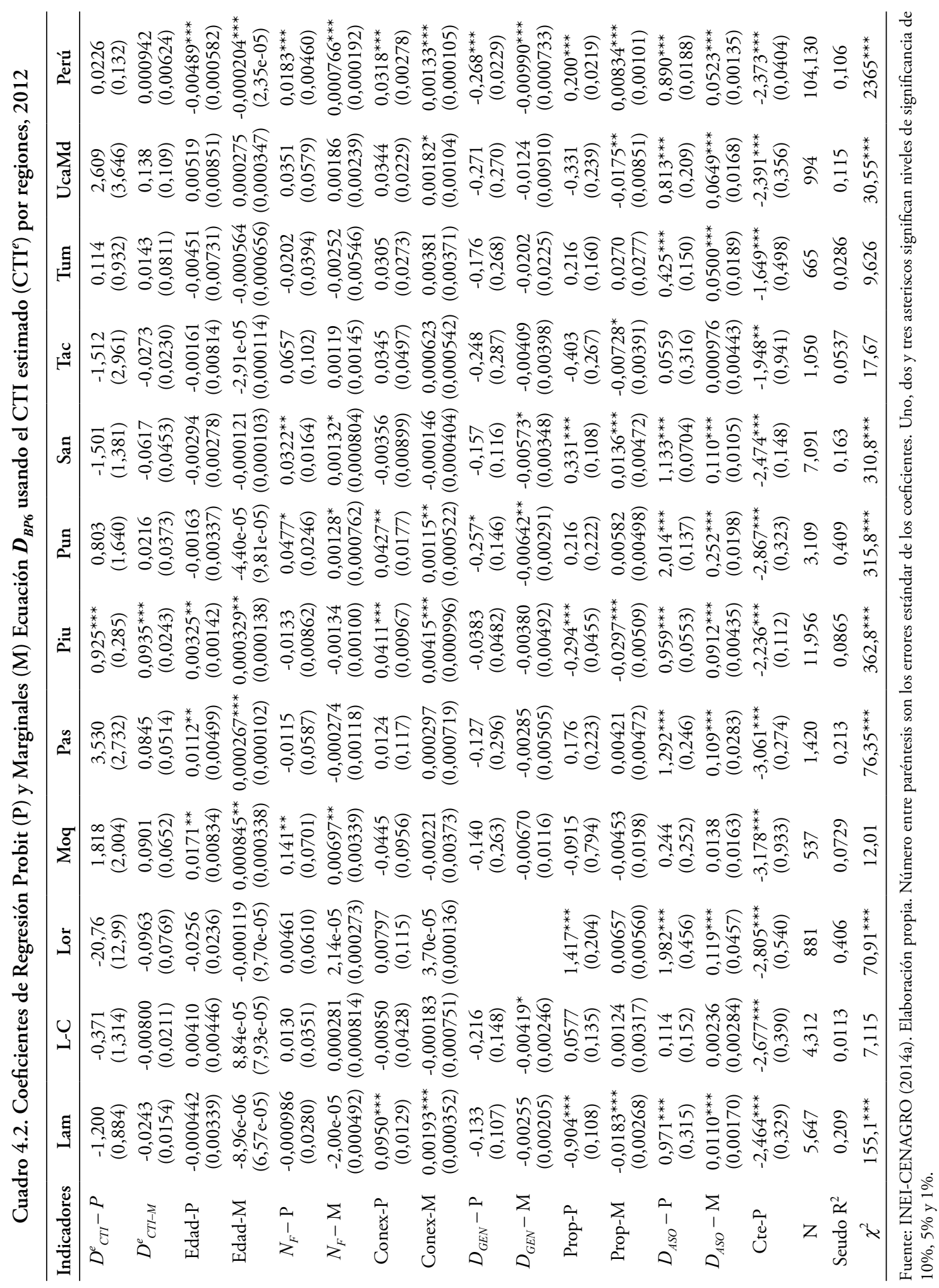


Cuadro 4.3. Coeficientes de regresión métodos MCO, Cuantiles 25\% y 75\%, Ordenado Logit (OLOG) y Probit (OPROB) de la Ecuación de Productividad Usando la Variable Binaria CTI para el Perú, 2012

\begin{tabular}{|c|c|c|c|c|c|c|c|c|c|c|}
\hline \multirow{2}{*}{$\begin{array}{l}\text { Variables } \\
\text { Métodos } \\
\end{array}$} & \multicolumn{5}{|c|}{ EDU } & \multicolumn{5}{|c|}{ SIN EDU } \\
\hline & MCO & Q25 & Q75 & OLOG & OPROB & MCO & Q25 & Q75 & OLOG & OPROB \\
\hline$D_{C T I}$ & $\begin{array}{l}0,244^{* * *} \\
(0,0437)\end{array}$ & $\begin{array}{l}0,205^{* * *} \\
(0,0560)\end{array}$ & $\begin{array}{c}0,335^{* * *} \\
(0,0333)\end{array}$ & $\begin{array}{l}0,296^{* * *} \\
(0,0345)\end{array}$ & $\begin{array}{l}0,170^{* * *} \\
(0,0202)\end{array}$ & $\begin{array}{l}0,196^{* * *} \\
(0,0433)\end{array}$ & $\begin{array}{c}0,112 \\
(0,0687)\end{array}$ & $\begin{array}{l}0,327^{* * *} \\
(0,0310)\end{array}$ & $\begin{array}{l}0,286^{* * *} \\
(0,0339)\end{array}$ & $\begin{array}{l}0,163^{* * *} \\
(0,0199)\end{array}$ \\
\hline$D_{B P 1}$ & $-0,400^{* * *}$ & $-0,657^{* * *}$ & $-0,0668^{* * *}$ & $-0,328^{* * *}$ & $-0,193^{* * *}$ & $-0,412^{* * *}$ & $-0,678^{* * *}$ & $-0,0697^{* * *}$ & $-0,331^{* * *}$ & $-0,194^{* * *}$ \\
\hline & $(0,0233)$ & $(0,0339)$ & $(0,00887)$ & $(0,0181)$ & $(0,0106)$ & $(0,0233)$ & $(0,0274)$ & $(0,0119)$ & $(0,0181)$ & $(0,0106)$ \\
\hline$D_{B P 2}$ & $\begin{array}{c}0,264^{* * *} \\
(0,0189)\end{array}$ & $\begin{array}{l}0,366^{* * *} \\
(0,0284)\end{array}$ & $\begin{array}{l}0,102^{* * *} \\
(0,0131)\end{array}$ & $\begin{array}{l}0,307^{* * *} \\
(0,0153)\end{array}$ & $\begin{array}{c}0,180^{* * *} \\
(0,00902)\end{array}$ & $\begin{array}{l}0,259^{* * *} \\
(0,0189)\end{array}$ & $\begin{array}{l}0,364^{* * *} \\
(0,0377)\end{array}$ & $\begin{array}{l}0,102^{* * *} \\
(0,0140)\end{array}$ & $\begin{array}{l}0,306^{* * *} \\
(0,0153)\end{array}$ & $\begin{array}{c}0,180^{* * *} \\
(0,00901)\end{array}$ \\
\hline$D_{B P 3}$ & $\begin{array}{c}0,0999^{* * *} \\
(0,0227)\end{array}$ & $\begin{array}{l}0,129^{* * *} \\
(0,0341)\end{array}$ & $\begin{array}{l}0,159^{* * *} \\
(0,0167)\end{array}$ & $\begin{array}{l}0,189^{* * *} \\
(0,0194)\end{array}$ & $\begin{array}{l}0,108^{* * *} \\
(0,0115)\end{array}$ & $\begin{array}{l}0,102^{* * *} \\
(0,0227)\end{array}$ & $\begin{array}{l}0,137^{* * *} \\
(0,0369)\end{array}$ & $\begin{array}{l}0,157^{* * *} \\
(0,0156)\end{array}$ & $\begin{array}{l}0,189^{* * *} \\
(0,0194)\end{array}$ & $\begin{array}{l}0,108^{* * *} \\
(0,0115)\end{array}$ \\
\hline$D_{B P 4}$ & $\begin{array}{c}-0,437^{* * *} \\
(0,0219)\end{array}$ & $\begin{array}{c}-0,459^{* * *} \\
(0,0346)\end{array}$ & $\begin{array}{c}-0,276^{* * *} \\
(0,0172)\end{array}$ & $\begin{array}{c}-0,339^{* * *} \\
(0,0185)\end{array}$ & $\begin{array}{c}-0,206^{* * *} \\
(0,0109)\end{array}$ & $\begin{array}{c}-0,438^{* * *} \\
(0,0219)\end{array}$ & $\begin{array}{c}-0,467^{* * *} \\
(0,0326)\end{array}$ & $\begin{array}{c}-0,276^{* * *} \\
(0,0151)\end{array}$ & $\begin{array}{c}-0,339^{* * *} \\
(0,0185)\end{array}$ & $\begin{array}{c}-0,206^{* * *} \\
(0,0109)\end{array}$ \\
\hline$D_{B P 5}$ & $\begin{array}{l}0,234^{* * *} \\
(0,0296)\end{array}$ & $\begin{array}{l}0,312^{* * *} \\
(0,0555)\end{array}$ & $\begin{array}{c}0,0942^{* * *} \\
(0,0240)\end{array}$ & $\begin{array}{l}0,165^{* * *} \\
(0,0251)\end{array}$ & $\begin{array}{l}0,100^{* * *} \\
(0,0148)\end{array}$ & $\begin{array}{l}0,232^{* * *} \\
(0,0296)\end{array}$ & $\begin{array}{l}0,310^{* * *} \\
(0,0519)\end{array}$ & $\begin{array}{c}0,0909^{* * *} \\
(0,0265)\end{array}$ & $\begin{array}{l}0,165^{* * *} \\
(0,0251)\end{array}$ & $\begin{array}{c}0,0998^{* * *} \\
(0,0148)\end{array}$ \\
\hline$D_{B P 6}$ & $\begin{array}{l}0,997^{* * *} \\
(0,0418)\end{array}$ & $\begin{array}{l}1,158^{* * *} \\
(0,0642)\end{array}$ & $\begin{array}{l}0,690^{* * *} \\
(0,0351)\end{array}$ & $\begin{array}{l}0,905^{* * *} \\
(0,0433)\end{array}$ & $\begin{array}{l}0,534^{* * *} \\
(0,0254)\end{array}$ & $\begin{array}{l}0,999^{* * *} \\
(0,0420)\end{array}$ & $\begin{array}{l}1,142^{* * *} \\
(0,0564)\end{array}$ & $\begin{array}{l}0,690^{* * *} \\
(0,0320)\end{array}$ & $\begin{array}{l}0,905^{* * *} \\
(0,0433)\end{array}$ & $\begin{array}{l}0,534^{* * *} \\
(0,0254)\end{array}$ \\
\hline $\begin{array}{l}\ln (\mathrm{T} / \mathrm{L}) \\
(\mathrm{Ha} / \mathrm{tra})\end{array}$ & $\begin{array}{c}0,795^{* * *} \\
(0,00574)\end{array}$ & $\begin{array}{c}0,768^{* * *} \\
(0,00622)\end{array}$ & $\begin{array}{c}0,854^{* * *} \\
(0,00379)\end{array}$ & $\begin{array}{c}0,741^{* * *} \\
(0,00558)\end{array}$ & $\begin{array}{c}0,432^{* * *} \\
(0,00313)\end{array}$ & $\begin{array}{c}0,795^{* * *} \\
(0,00575)\end{array}$ & $\begin{array}{c}0,767^{* * *} \\
(0,00872)\end{array}$ & $\begin{array}{c}0,855^{* * *} \\
(0,00383)\end{array}$ & $\begin{array}{c}0,741^{* * *} \\
(0,00558)\end{array}$ & $\begin{array}{c}0,432^{* * *} \\
(0,00313)\end{array}$ \\
\hline lnDCult & $\begin{array}{c}-0,307^{* * *} \\
(0,0131)\end{array}$ & $\begin{array}{c}-0,105^{* * *} \\
(0,0217)\end{array}$ & $\begin{array}{c}-0,656^{* * *} \\
(0,0124)\end{array}$ & $\begin{array}{c}-0,114^{* * *} \\
(0,0114)\end{array}$ & $\begin{array}{c}-0,0565^{* * *} \\
(0,00678)\end{array}$ & $\begin{array}{c}-0,309^{* * *} \\
(0,0130)\end{array}$ & $\begin{array}{c}-0,111^{* * *} \\
(0,0205)\end{array}$ & $\begin{array}{l}-0,658^{* * *} \\
(0,00679)\end{array}$ & $\begin{array}{c}-0,114^{* * *} \\
(0,0114)\end{array}$ & $\begin{array}{c}-0,0569^{* * *} \\
(0,00678)\end{array}$ \\
\hline $\operatorname{lnEdad}$ & $\begin{array}{c}-0,583^{* * *} \\
(0,0244)\end{array}$ & $\begin{array}{c}-0,924^{* * *} \\
(0,0347)\end{array}$ & $\begin{array}{c}-0,231^{* * *} \\
(0,0181)\end{array}$ & $\begin{array}{c}-0,516^{* * *} \\
(0,0214)\end{array}$ & $\begin{array}{c}-0,298^{* * *} \\
(0,0127)\end{array}$ & $\begin{array}{c}-0,508^{* * *} \\
(0,0220)\end{array}$ & $\begin{array}{c}-0,815^{* * *} \\
(0,0358)\end{array}$ & $\begin{array}{c}-0,213^{* * *} \\
(0,0108)\end{array}$ & $\begin{array}{c}-0,501^{* * *} \\
(0,0194)\end{array}$ & $\begin{array}{c}-0,288^{* * *} \\
(0,0115)\end{array}$ \\
\hline $\operatorname{lnEdu}$ & $\begin{array}{c}-0,159^{* * *} \\
(0,0229)\end{array}$ & $\begin{array}{c}-0,241^{* * *} \\
(0,0333)\end{array}$ & $\begin{array}{c}-0,0386^{* * *} \\
(0,0146)\end{array}$ & $\begin{array}{c}-0,0316 \\
(0,0194)\end{array}$ & $\begin{array}{c}-0,0221^{*} \\
(0,0115)\end{array}$ & & & & & \\
\hline$D_{G E N}$ & $\begin{array}{c}-0,0449^{* *} \\
(0,0189)\end{array}$ & $\begin{array}{c}-0,0590^{*} \\
(0,0347)\end{array}$ & $\begin{array}{l}0,00331 \\
(0,0144)\end{array}$ & $\begin{array}{c}-0,0194 \\
(0,0160)\end{array}$ & $\begin{array}{c}-0,0106 \\
(0,00953)\end{array}$ & $\begin{array}{l}-0,0227 \\
(0,0187)\end{array}$ & $\begin{array}{l}-0,0236 \\
(0,0305)\end{array}$ & $\begin{array}{c}0,0100 \\
(0,0117)\end{array}$ & $\begin{array}{c}-0,0147 \\
(0,0158)\end{array}$ & $\begin{array}{l}-0,00742 \\
(0,00939)\end{array}$ \\
\hline lnConex & $\begin{array}{c}-0,159^{* * *} \\
(0,0146)\end{array}$ & $\begin{array}{c}-0,115^{* * *} \\
(0,0184)\end{array}$ & $\begin{array}{l}-0,228^{* * *} \\
(0,00907)\end{array}$ & $\begin{array}{c}-0,152^{* * *} \\
(0,0121)\end{array}$ & $\begin{array}{c}-0,0852^{* * *} \\
(0,00719)\end{array}$ & $\begin{array}{c}-0,147^{* * *} \\
(0,0144)\end{array}$ & $\begin{array}{c}-0,0920^{* * *} \\
(0,0261)\end{array}$ & $\begin{array}{l}-0,224^{* * *} \\
(0,00653)\end{array}$ & $\begin{array}{c}-0,150^{* * *} \\
(0,0120)\end{array}$ & $\begin{array}{c}-0,0836^{* * *} \\
(0,00714)\end{array}$ \\
\hline $\begin{array}{c}\operatorname{lnClima} \\
(\mathrm{Ha} / \mathrm{E})\end{array}$ & $\begin{array}{c}-0,0308^{* * *} \\
(0,00595)\end{array}$ & $\begin{array}{l}-0,00232 \\
(0,00855)\end{array}$ & $\begin{array}{c}-0,0710^{* * *} \\
(0,00262)\end{array}$ & $\begin{array}{c}-0,0328^{* * *} \\
(0,00465)\end{array}$ & $\begin{array}{c}-0,0199^{* * *} \\
(0,00274)\end{array}$ & $\begin{array}{c}-0,0295^{* * *} \\
(0,00595)\end{array}$ & $\begin{array}{c}-0,000378 \\
(0,00632)\end{array}$ & $\begin{array}{c}-0,0712^{* * *} \\
(0,00263)\end{array}$ & $\begin{array}{c}-0,0326^{* * *} \\
(0,00465)\end{array}$ & $\begin{array}{r}-0,0197^{* * *} \\
(0,00274)\end{array}$ \\
\hline $\operatorname{lnProp}(\%)$ & $\begin{array}{l}0,312^{* * *} \\
(0,0338)\end{array}$ & $\begin{array}{l}0,343^{* * *} \\
(0,0624)\end{array}$ & $\begin{array}{l}0,261^{* * *} \\
(0,0305)\end{array}$ & $\begin{array}{l}0,223^{* * *} \\
(0,0291)\end{array}$ & $\begin{array}{l}0,133^{* * *} \\
(0,0175)\end{array}$ & $\begin{array}{l}0,315^{* * *} \\
(0,0338)\end{array}$ & $\begin{array}{l}0,338^{* * *} \\
(0,0589)\end{array}$ & $\begin{array}{l}0,262^{* * *} \\
(0,0174)\end{array}$ & $\begin{array}{l}0,223^{* * *} \\
(0,0291)\end{array}$ & $\begin{array}{l}0,133^{* * *} \\
(0,0175)\end{array}$ \\
\hline Const $/ \lambda_{1}{ }^{1}$ & $\begin{array}{c}8,749^{* * * *} \\
(0,114)\end{array}$ & $\begin{array}{c}9,222^{* * *} \\
(0,153)\end{array}$ & $\begin{array}{l}8,609^{* * *} \\
(0,0831)\end{array}$ & $\begin{array}{c}-3,741^{* * *} \\
(0,100)\end{array}$ & $\begin{array}{c}-2,164^{* * *} \\
(0,0594)\end{array}$ & & & & $\begin{array}{c}-3,635^{* * *} \\
(0,0762)\end{array}$ & $\begin{array}{c}-2,090^{* * *} \\
(0,0451)\end{array}$ \\
\hline$\lambda_{2}{ }^{1}$ & & & & $\begin{array}{c}-2,402^{* * *} \\
(0,0996)\end{array}$ & $\begin{array}{c}-1,374^{* * *} \\
(0,0591)\end{array}$ & & & & $\begin{array}{c}-2,296^{* * *} \\
(0,0755)\end{array}$ & $\begin{array}{r}-1,300^{* * *} \\
(0,0449)\end{array}$ \\
\hline$\lambda_{3}{ }^{1}$ & & & & $\begin{array}{c}-0,988^{* * *} \\
(0,0993)\end{array}$ & $\begin{array}{c}-0,534^{* * *} \\
(0,0591)\end{array}$ & & & & $\begin{array}{c}-0,882^{* * *} \\
(0,0751)\end{array}$ & $\begin{array}{c}-0,460^{* * *} \\
(0,0448)\end{array}$ \\
\hline Obs & 76,494 & 76,494 & 76,494 & 76,494 & 76,494 & 76,494 & 76,494 & 76,494 & 76,494 & 76,494 \\
\hline Seudo $\mathrm{R}^{2}$ & 0,24 & 0,11 & 0,25 & 0,11 & 0,11 & 0,24 & 0,11 & 0,25 & 0,11 & 0,11 \\
\hline$\chi^{2}$ & & & & $23444^{* * *}$ & $23135^{* * *}$ & & & & $23441^{* * *}$ & $23131^{* * *}$ \\
\hline $\mathrm{F}$ & $1610^{* * *}$ & & & & & $1720^{* * *}$ & & & & \\
\hline
\end{tabular}

Fuente: INEI-CENAGRO (2014a), INEI-ENAPRES (2014), INEI-ENAHO (2014), INDECI (2014). * **, **, Significativo al 10\%, 5\% y $1 \%$. Errores estándar en paréntesis. ${ }^{1}$ Los parámetros $\lambda$ corresponde a los limites siguientes: $0<\ln P L^{*} \leq \lambda_{1}\left[\right.$ Prob $\left.\left(D_{P L}=1\right)\right] ; \lambda_{1}<\operatorname{lnPL}{ }^{*} \leq \lambda_{2}[$ Prob $\left.\left(D_{P L}=2\right)\right] ; \lambda_{2}<\ln P L^{*} \lambda_{3}\left[\operatorname{Prob}\left(D_{P L}=3\right)\right] ; \operatorname{lnPL}{ }^{*}>\lambda_{3}\left[\operatorname{Prob}\left(D_{P L}=4\right)\right]$, donde $\operatorname{lnPL}{ }^{*}$ es una distribución normal o logit estándar. 
Dado el efecto positivo de la experiencia, lo que posiblemente explica el efecto negativo del grado de propiedad del agricultor es el bajo nivel educativo de los agricultores que tienen un mayor grado de decisión sobre sus parcelas. En el caso del efecto del género, los resultados fueron mixtos. Para la mitad de las prácticas tecnológicas (específicamente $D B P_{1}, D B P_{5}$ y $\left.D B P_{6}\right)$ los jefes de familia mujeres tuvieron una menor probabilidad de uso de estas prácticas que los hombres. Para dos de estas prácticas $\left(D B P_{2}\right.$ y $\left.D B P_{3}\right)$, las mujeres tuvieron una mayor probabilidad de uso de estas prácticas. Para las prácticas $\mathrm{DBP}_{4}$ el género no influyó en las decisiones de uso de esta buena práctica tecnológica. A excepción de la variable CTI, la cual el $70 \%$ de los coeficientes de esta variable del total de coeficientes (correspondientes a las 6 buenas prácticas y las 23 regiones ${ }^{44}$ de las regiones del Perú) fueron positivos y estadísticamente significativos en las estimaciones de las ecuaciones de la difusión tecnológica de las buenas prácticas, los resultados de los efectos sobre la difusión de las buenas prácticas tecnológicas del resto de variables fueron diversos a nivel de regiones.

La variabilidad de los efectos regionales de las variables determinantes de la capacidad tecnológica y de innovación y la difusión de las buenas prácticas tecnológicas sugieren que políticas horizontales o homogéneas en las regiones no sería efectivas para el fomento de estos aspectos tecnológicos. Las propias regiones requieren identificar las políticas que serían más efectivas para el fomento de dichos aspectos tecnológicos.

Con respecto a los determinantes de la productividad laboral, los resultados de las estimaciones de la ecuación [2.3] indican que independientemente de los métodos de estimación aplicados, la capacidad tecnológica y de innovación, y el uso de abonos, fertilizantes, control de plagas y certificaciones incidieron positiva y de manera estadísticamente significativa a la productividad laboral de los agricultores, PL. De manera análoga, la propiedad de las parcelas y la productividad de la tierra (ratio tierra por trabajador) incidieron positiva y significativamente sobre la PL. Con efectos negativos aunque estadísticamente significativos se obtuvieron con las variables de experiencia del agricultor $^{45}$, la diversificación de cultivos, el clima, y la distancia geográfica entre el lugar de producción y la capital de la región. La variable genero sugiere, que la evidencia no fue clara respecto a las diferencias de productividad laboral entre unidades productivas lideradas por jefes de familia hombres y mujeres ${ }^{46}$.

Los resultados con respecto al capital humano y el uso de semillas e insecticidas fueron inesperados. Desde el punto de vista estadístico, estos pueden deberse a la colinealidades presentes entre estas variables y la variable binaria de la capacidad tecnológica

\footnotetext{
${ }^{44}$ Cabe reiterar que las regiones de Lima y Callao y Ucayali y Madre de Dios han sido agrupadas en solo dos regiones.

45 Note que el promedio de edad de los jefes de familia es cerca de 50 años. Estos implica que una alta proporción de la muestra es mayor a 50 años. Al igual que el caso de la difusión del uso de las buenas prácticas tecnológicas es posible que exista no linealidades en los efectos de experiencia sobre la productividad laboral. 46 Tello (2014a) encuentra los mismos resultados para una muestra de 4310 jefes de familia.
} 
y de innovación. Cabe además señalar que el nivel mínimo de educación es un determinante de $D_{C T I}$ y por consiguiente esta variable también captura parte de la incidencia del capital humano ${ }^{47}$. Otra explicación de la incidencia negativa del uso de semillas certificadas e insecticidas es propuesta por Arza, Goldberg y Vazquez (2012). Ellos arguyen que son los paquetes tecnológicos agricolas ${ }^{48}$ los que inciden positivamente sobre la PL. Consecuentemente, los elementos parciales o incompletos de dichos paquetes (como por ejemplo solo usar semillas certificadas o insecticidas) no necesariamente aseguran los efectos positivos sobre la PL. Bajo esta interpretación, el signo negativo de los coeficientes de las prácticas tecnológicas de uso de semillas certificadas e insecticidas puede ser interpretado como un resultado espurio o que el uso incompleto de los paquetes tecnológicos agrarios no tiene una incidencia positiva sobre la PL. Cabe señalar que para la muestra total del Perú y para la mayoría de regiones, en promedio más de la mitad de los agricultores hacen uso de las prácticas tecnológicas de abonos orgánicos, fertilizantes químicos, e insecticidas. Por otro lado, la magnitud de la suma de los efectos del uso de estas prácticas tecnológicas conjuntamente con el uso de semillas certificadas no compensa la magnitud de los efectos de las prácticas tecnológicas del uso de control de plagas y certificaciones orgánicas ${ }^{49}$. Estas dos prácticas, en promedio, solo son usadas por menos del $8 \%$ de los productores de la agricultura moderna y son las que tienen mayores efectos positivos sobre la PL.

$\mathrm{Al}$ igual que el caso del uso de las buenas prácticas tecnológicas y la capacidad tecnológica y de innovación los resultados no reportados a nivel de regiones son muy heterogéneos. Sin embargo, a diferencia de los resultados descritos sobre estas variables tecnológicas, la incidencia positiva de la productividad de la tierra resultó estadísticamente significativa para todos los métodos y regiones del Perú. Consistente con las cifras de bajo crecimiento de la productividad total factorial y bajos niveles de innovación, de la capacidad tecnológica y de innovación (del Perú y de los agricultores comerciales modernos), y gastos en $I \& D$ en 2012 , este resultado sugiere que la productividad laboral en el campo es determinada fundamentalmente por la productividad de las tierras.

Los resultados de las estimaciones presentadas, sujeto a las limitaciones de la información y métodos utilizados, muestran dos aspectos que se requiere tomar en cuenta en el desarrollo agrícola de los pequeños productores de las regiones del Perú. El primero es el de la heterogeneidad de efectos de los factores que supuestamente inciden de manera positiva en la CTI, difusión de buenas prácticas tecnológicas y la productividad laboral.

\footnotetext{
47 En las estimaciones de Tello (2014a) con una muestra de 4310 de agricultores agropecuarios la cual no incorpora la variable $D_{C T I}$ el coeficiente de la variable capital humano sobre la PL fue positivo y estadísticamente significativo.

48 Este paquete tecnológico incluye buenas prácticas agronómicas, insumos específicos y maquinaria moderna.

49 Notar que la suma de los coeficientes de las seis buenas prácticas tecnológicas es positiva y estadísticamente significativa.
} 
Estas diferencias de efectos pueden deberse a aspectos relacionados con la capacidad empresarial de los productores, las condiciones propias de los cultivos y de las tierras, a las calidades y capacidad de uso por parte de los productores de las buenas prácticas tecnológicas y paquetes tecnológicos agrícolas entre muchos otros. Esta heterogeneidad de efectos implica que la política agraria requiere ser específica de acuerdo al lugar de los centros de producción en lugar de ser transversal e igual para todos los centros a lo largo del territorio peruano. El segundo aspecto es que a pesar de las limitaciones de las medidas usadas, la capacidad tecnológica y de innovación, y ciertas buenas prácticas tecnológicas parecen ser factores fundamentales para obtener incrementos sustanciales de la productividad laboral agrícola y que pueden compensar el efecto del bajo tamaño de la tierra cultivada por trabajador. Los niveles de CTI, el control de plagas $\left(D B P_{5}\right)$ y la obtención de certificaciones orgánicas $\left(D B P_{6}\right)$ para la mayor parte de las regiones han sido muy bajos y menos del $8 \%$ de los productores agrícolas de la muestra analizada contaban con estos factores tecnológicos. En consecuencia, dos de los potenciales roles de la política agraria son el de fomentar dichas capacidades y difundir el uso de dichas buenas prácticas tecnológicas de manera transversal a los productores de las regiones del Perú.

\section{CONCLUSIONES}

El presente trabajo, de naturaleza exploratoria, ha analizado y estimado las interrelaciones entre la capacidad tecnológica y de innovación (CTI), la difusión de buenas prácticas tecnológicas y la productividad laboral de unidades productivas del sector agrícola comprendido por jefes de familia de condición jurídica de persona natural los cuales venden su producción al mercado (interno y/o externo). La fuente primaria y básica de información de estos productores de la agricultura comercial moderna ha sido el Censo Nacional Agropecuario de 2012 (INEI-CENAGRO, 2014a). Con esta fuente y otras complementarias se estimaron las especificaciones ad hoc de la capacidad tecnológica y de innovación, la difusión de las seis buenas prácticas tecnológicas, y la productividad laboral de los productores de la agricultura comercial moderna.

Los resultados de estas estimaciones señalan en primer lugar, que el tamaño de la unidad productiva, el capital humano acumulado (en niveles de educación) del productor y la distancia geográfica fueron los principales factores que incidieron en la capacidad tecnológica y de innovación. Segundo, esta capacidad conjuntamente con los efectos de derramamiento (spillover effects) derivados de las asociaciones de los agricultores determinaron el uso y difusión de las seis buenas prácticas tecnológicas. Tercero, el stock de tierras por trabajador fue el principal determinante de la productividad laboral para las observaciones de cada una de las regiones del Perú. A nivel de Perú, el porcentaje de parcelas de propiedad del agricultor, la distancia geográfica, las inclemencias del clima, la capacidad tecnológica y de innovación, niveles bajos de diversificación productiva y el uso de las buenas prácticas tecnológicas (excepto el uso de semillas e insecticidas) 
también incidieron (positiva y estadísticamente) sobre la productividad laboral. Sin embargo, estas incidencias variaron por región.

Como conclusión final y a manera de información para los hacedores de política económica, fomentar la capacidad tecnológica y de innovación en la agricultura comercial moderna puede requerir entre otras cosas de: i) acceso al crédito para financiar capital y herramientas, ii) apoyo en asistencia técnica ${ }^{50}$, y iii) del incremento del nivel de educativo de los emprendedores agrícolas. Los factores que definen esta capacidad en el presente estudio indican que en 2012 solo el 4,6\% de la muestra de productores de agricultura comercial moderna posiblemente tendrían dicha capacidad. Esta capacidad conjuntamente con el uso de certificaciones orgánicas y el control de plagas puede además aumentar de manera sustantiva la productividad laboral del agricultor peruano y compensar a aquellos que tienen bajos niveles de stock de tierra por trabajador.

\section{REFERENCIAS}

Alene, A. (2010). Productivity growth and the effects of R\&D in African agriculture. Agricultural Economics, 41, 223-238. http://dx.doi.org/10.1111/j.1574-0862.2010.00450.x

Alston, J. M. (2010). The Benefits from Agricultural Research and Development, Innovation, and Productivity Growth. OECD Food, Agriculture and Fisheries Papers, No. 31, OECD Publishing. http://dx.doi.org/10.1787/5km91nfsnkwg-en

Alvarez, José, Claudio D’Ipollito y Einstein Lemos de Aguilar (2009). Estudio de caso innovador: Pisco Payet. Mimeo, Lima.

Arza, V., L. Goldberg y C. Vazquez (2012). Argentina: difusión del algodón GM e impacto en la rentabilidad de los pequeños productores de la Provincia del Chaco. Revista CEPAL, 107(agosto), 137-156.

Assunção, J. J. y L. H. B. Braido (2007). Testing Household-Specific Explanations for the Inverse Productivity Relationship. American Journal of Agricultural Economics, 89(4), 980-990. http://dx.doi.org/10.1111/j.1467-8276.2007.01032.x

Ayalew, D., K. Deininger (2014). There a Farm-Size Productivity Relationship in African Agricul- ture? Evidence from Rwanda. Policy Research Working Paper No. 677. The World Bank Development Research Group. http://dx.doi.org/10.1596/1813-9450-6770

Barrett, C. B., M. F. Bellemare and J. Y. Hou (2010). Reconsidering Conventional Explanations of the Inverse Productivity-Size Relationship. World Development 38(1), 88-97. http:// dx.doi.org/10.1016/j.worlddev.2009.06.002

Barro, R., X. Sala-Martín (1995). Technological Diffusion, Convergence, and Growth. NBER, WP No. 5151. http://dx.doi.org/10.3386/w5151

Bell, Martin y Keith Pavitt (1993). Technological Accumulation and Industrial Growth: Contrasts Between Developed and Developing Countries. Industrial and Corporate Change, 2(2), 157-210. http://dx.doi.org/10.1093/icc/2.1.157.

BID, CEPAL, OEA (2011). Experiencias exitosas en innovación, inserción internacional e inclusión social: una mirada a las pymes. Santiago de Chile: CEPAL.

\footnotetext{
50 Esta información no proviene de los resultados estadísticos sino más bien del bajísimo porcentaje de jefes de familia en la muestra que tuvieron acceso a dichos créditos.
} 
Cohen, W. M. \& Levinthal, D. A. (1990). Absorptive capacity: A new perspective on learning and innovation. Administrative Science Quarterly, 35, 128-153. http://dx.doi. org/10.2307/2393553

Conference Board (2014). Economic Data Base. Disponible en

Crepon, B., E. Duguet and J. Mairesse (1998). Research, Innovation and Productivity: An Econometric Analysis at the Firm Level. Economics of Innovation and New Technology, 7(2), 115-158. http://dx.doi.org/10.3386/w6696

Damonte, G., Fulcrand, B. y Gómez, R. (2008). Perú: el problema agrario en debate. SEPIA XII. Lima: Seminario Permanente de Investigación Agraria - SEPIA.

Del Castillo, C., K. Oviedo (2009). Innovación de la agroindustria rural mediante el mejoramiento el cultivo; cosecha y post cosecha del banano orgánico en la Central Piurana de Asociaciones de Pequeños Productores de Banano Orgánico CEPIBO. CIES, mimeo.

Dhehibi, B., R. Telleria, A. Aw-Hassan (2014). Total Factor Productivity in Tunisian Agriculture: Measurement and Determinants. New Medit, 1, 4-14.

Escobal, J. (2000). Costos de transacción en la agricultura peruana: una primera aproximación a su medición e impacto. Documento de trabajo 30. Lima: Grupo de Análisis para el Desarrollo.

Evenson, R., P. Pingali (2009). Handbook of Agricultural Economics. Vol 3. North Holland.

FINCyT-CIES (2010). Innovación Empresarial y Comportamiento Tecnológico Sectorial: Experiencias exitosas y estudio de casos. Programa de Ciencia y Tecnología - FINCyT y Consorcio de Investigación Económica y Social, Diagnóstico y Propuesta 47, Lima-Perú.

Gardner, B., G. Rausser (2002). Handbook of Agricultural Economics. Vol. 1 y 2. North Holland.

Geroski, P. A. (2000). Models of technology diffusion. Research Policy, 29(4-5), 603-625. http:// dx.doi.org/10.1016/s0048-7333(99)00092-x

Gómez, R. (2008). Agricultura comercial moderna en el Perú. El caso de la agricultura de exportación no tradicional (1995-2007). En G. Damonte, B. Fulcrand y R. Gómez, Perú: el problema agrario en debate. SEPIA XII. Lima: Seminario Permanente de Investigación Agraria - SEPIA.

Griliches, Z. (1957). Hybrid Corn: An Exploration in the Economics of Technological Change. Econometrica, 25, 501-522. http://dx.doi.org/10.2307/1905380

Guirkinger, C., S. Boucher (2008). Credit constraints and productivity in Peruvian agriculture. Agricultural Economics, 39, 295-308. http://dx.doi.org/10.1111/j.15740862.2008.00334.x

Hall, B. (2004). Innovation and Diffusion. NBER WP, No 10212. Cambridge, MA: NBER. http://dx.doi.org/10.3386/w10212

Hall, B. (2011). Innovation and Productivity. NBER WP, No 17178. Cambridge, MA: NBER. http://dx.doi.org/10.3386/w17178

Hall, B., N. Rosenberg (2010). Handbook of the Economics of Innovation, Vol. 1 y 2. North Holland.

HDE (1988-2010). Handbook of Development Economics, Vol. 1-5. Eds. H. Chenery, y T.N. Srinivasan, Vol. 1 y 2; T.N. Srinivasan, J. Behrman, Vol. 3 y 4; D. Rodrik y M. Rosenzweig, Vol. 5. North Holland. https://www.conference-board.org/data/economydatabase/

Huarachi, J., B. Vargas, P. Yamakawa, J. Perez, N. Larrea Valencia (2010). Diagnóstico del estado de la innovación en el sector agroindustrial de exportación en el Perú. En FINCyT-CIES, Innovación Empresarial y Comportamiento Tecnológico Sectorial: Experiencias exitosas y estudio de casos. Programa de Ciencia y Tecnología - FINCyT y Consorcio de Investigación Económica y Social, Diagnóstico y Propuesta 47, Lima-Perú. 
ICLS-ILO (1993). 15th International Conference of Labor Statisticians. International Labour Office.

Kuramoto, J. (2010). Prácticas exitosas de innovación empresarial y comportamiento tecnológico sectorial. En FINCyT-CIES, 2010. Innovación Empresarial y Comportamiento Tecnológico Sectorial: Experiencias exitosas y estudio de casos, Capítulo I. Programa de Ciencia y Tecnología - FINCyT y Consorcio de Investigación Económica y Social, Diagnóstico y Propuesta 47, Lima-Perú.

Lagakos D., M. Waugh (2013). Selection, Agriculture, and Cross-Country Productivity Differences. American Economic Review, 103(2), 948-980. http://dx.doi.org/10.1257/ aer.103.2.948

Ludeña, C. (2010). Agricultural Productivity Growth, Efficiency Change and Technical Progress in Latin America and the Caribbean. IDB-WP-186. http://dx.doi.org/10.2139/ ssrn. 1817296

Martínez, C., M. Rodríguez, M. Almeida (2009). La innovación tecnológica en el desarrollo de familias campesinas dedicadas a la agroindustria: el caso de la empresa Micaela Bastidas, distrito de Pampamarca, provincia de Canas, región Cusco. En FINCyT-CIES, 2010. Innovación Empresarial y Comportamiento Tecnológico Sectorial: Experiencias exitosas y estudio de casos, Capítulo I. Programa de Ciencia y Tecnología - FINCyT y Consorcio de Investigación Económica y Social, Diagnóstico y Propuesta 47, Lima Perú.

OECD (2011). Fostering Productivity and Competitiveness in Agriculture. OECD Publishing. http://dx.doi.org/10.1787/9789264166820-en

OECD (2012). Agricultural Policy Monitoring and Evaluation 2012: OECD Countries, OECD Publishing. http://dx.doi.org/10.1787/agr_pol-2012-en

Pardey, P., J. Alston y V. Ruttan (2010). The Economics of Innovation and Technical Change in Agriculture. En B. Hall, N. Rosenberg, Handbook of the Economics of Innovation, Vol. 1 y 2. North Holland, Capítulo 22. http://dx.doi.org/10.1016/s0169-7218(10)02006-x

PIADAL (2013). Agricultura y desarrollo en América Latina: gobernanza y politicas públicas. (Diversos autores: Barrantes, R., Berdegué, J., De Janvry, A., Díaz-Bonilla, E., Elizondo, D., Gordillo, G., Ibáñez, A.M., Junguito, R., Hertford, R., Moscardi, E., Piñeiro, M., Pomareda, C., Valdés, A., Villasuso, J.M., y Yúnez-Naude, A). Buenos Aires: Teseo.

Pollyzos, S., G. Arabatsis (2006). Labor Productivity of the Agricultural Sector in Greece: Determinant Factors and Interregional Differences Analysis. New Medit (A Mediterranean Journal of Economics, Agriculture and Environment), 58-65.

Rogers, E. M. (1995). Diffusion of innovations (4th ed.). Nueva York: The Free Press.

Rosenberg, N. (1972). Factors affecting the diffusion of technology. Explorations in Economic History, 10, 3-33. http://dx.doi.org/10.1016/0014-4983(72)90001-0

Sen, A. (1999). Development as Freedom. Oxford, NY: Oxford University Press.

Stata (2016). Estimation and post-estimation commands. Disponible en http://www.stata.com/ manuals13/u20.pdf\#u20.21Obtainingrobustvarianceestimates

Stoneman, P. (2002). The Economics of Technological Diffusion. Oxford: Blackwell.

Syverson, C. (2011). What Determines Productivity? Journal of Economic Literature, 49(2), 326-365. http://dx.doi.org/10.1257/jel.49.2.326

Taylor, E., I. Adelman (2003). Agricultural Household Models: Genesis, Evolution, and Extensions. Review of Economics of the Household, 1(1), 33-58. http://dx.doi. org/10.1023/A:1021847430758

Tello, M. D. (2013). Costos de entrada a la exportación, diversificación y productividad: un enfoque a nivel de firmas manufactureras del Perú. Economía y Sociedad, 82, CIES. 
Tello, M. D. (2014a). “Cerrando Brechas de Género en el Campo: Limitantes de la Productividad Laboral de Mujeres Emprendedoras Agropecuarias en el Perú: Un Análisis Regional, 2012”. Informe Final, INEI, Movimiento Manuela Ramos.

Tello, M. D. (2014b). La productividad del sector manufacturero en el Perú: 2000-2010. Lima: INEI.

Torres, Fidel (2009). Prácticas tecnológicas y organizacionales exitosas de CEPICAFE en la innovación del azúcar integral ecológica de exportación en el norte del Perú. Mimeo. Lima.

Trivelli, C., Escobal, J. y Revesz, B. (2009). Desarrollo rural en la sierra. Aportes para el debate. Lima: Consorcio de Investigación Económica y Social - CIES, Centro de Investigación y Promoción del Campesinado - CIPCA, Grupo de Análisis para el Desarrollo - GRADE, Instituto de Estudios Peruanos - IEP.

Trivelli, C., Escobal, J. y Revesz, B. (2006). Pequeña agricultura comercial: dinámica y retos en el Perú. Lima: Consorcio de Investigación Económica y Social - CIES, Centro de Investigación y Promoción del Campesinado - CIPCA, Grupo de Análisis para el Desarrollo - GRADE, Instituto de Estudios Peruanos - IEP.

Warr, P., W. Suphannachart (2011). Research and productivity in Thai agriculture. The Australian Journal of Agricultural and Resource Economics, 55, 35-52. http://dx.doi.org/10.1111/ j.1467-8489.2010.00519.x

Webb, R. (2013). Conexión y despegue rural. Lima: Instituto del Perú, Universidad San Martín de Porres.

WEF (2014). Global Competitiveness Report, 2012-2013. World Economic Forum.

World Bank (2012). Agricultural Innovation Systems: An Investment Source Book. Washington, DC: World Bank. http://dx.doi.org/10.1596/978-0-8213-8684-2

Zahra, S. y G. George (2002). Absorptive capacity: A review, reconceptualization and extension. Academy of Management Review, 27(2), 185-203.

Zant, W. (2014). Do Organic Inputs in African Subsistence Agriculture Raise Productivity? Evidence from Plot Data of Malawi Household Surveys. Tinbergen Institute Discussion Paper, TI 2014-114/V. Amsterdam: Tinbergen Institute. http://dx.doi.org/10.2307/4134351

\section{Fuentes de base de datos}

Instituto Nacional de Defensa Civil. Estadísticas de Emergencias - Cuadros Estadísticos, INDECI. 2014. Disponible en http://sinpad.indeci.gob.pe/ReportServer/Pages/ReportViewer.aspx ?\%2fSINPAD\%2fEstadistica\%2fRpt_Estadistica_c12\&rs\%3aCommand=Render

INEI-CENAGRO, 2014. IV Censo Nacional Agropecuario 2012. Instituto Nacional de Estadística e Informática. Disponible en: http://proyectos.inei.gob.pe/cenagro/ tabulados/?id=CensosNacionales

INEI-CENAGRO, 2014a. IV Censo Nacional Agropecuario 2012. http://iinei.inei.gob.pe/ microdatos/

INEI, 2014b. Series Regionales. Disponible en < http://webinei.inei.gob.pe:8080/SIRTOD/\#>

INEI-ENAPRES 2014. Encuesta Nacional de Programas Estratégicos, 2012.

INEI-ENAHO, 2014. Encuesta Nacional de Hogares 2012.

Ministerio de Agricultura y Regio, MINAGRI. 2014. Series Históricas. Disponible en < http:// frenteweb.minag.gob.pe/sisca/?mod=consulta_cult> 